\title{
Spawning Characteristics of Yellow Perch during Periods of Water Level Fluctuations in a Hydropower Reservoir
}

Kyle J. Matt

kjmatt@mix.wvu.edu

Follow this and additional works at: https://researchrepository.wvu.edu/etd

Part of the Environmental Sciences Commons

\section{Recommended Citation}

Matt, Kyle J., "Spawning Characteristics of Yellow Perch during Periods of Water Level Fluctuations in a Hydropower Reservoir" (2020). Graduate Theses, Dissertations, and Problem Reports. 7960.

https://researchrepository.wvu.edu/etd/7960

This Thesis is protected by copyright and/or related rights. It has been brought to you by the The Research Repository @ WVU with permission from the rights-holder(s). You are free to use this Thesis in any way that is permitted by the copyright and related rights legislation that applies to your use. For other uses you must obtain permission from the rights-holder(s) directly, unless additional rights are indicated by a Creative Commons license in the record and/ or on the work itself. This Thesis has been accepted for inclusion in WVU Graduate Theses, Dissertations, and Problem Reports collection by an authorized administrator of The Research Repository @ WVU. For more information, please contact researchrepository@mail.wvu.edu. 
Spawning Characteristics of Yellow Perch during Periods of Water Level Fluctuations in a Hydropower Reservoir

Kyle J. Matt

Follow this and additional works at: https://researchrepository.wvu.edu/etd

Part of the Environmental Sciences Commons 
Spawning Characteristics of Yellow Perch during Periods of Water Level Fluctuations in a Hydropower Reservoir

Kyle J. Matt

A Thesis Submitted to the

Davis College of Agriculture, Natural Resources, and Design

at West Virginia University

in partial fulfillment of the requirements

for the degree of

Master of Science

In

Wildlife and Fisheries Resources

Stuart A. Welsh, Ph.D., Chair

Kyle J. Hartman, Ph.D.

Dustin M. Smith, Ph.D.

Division of Forestry and Natural Resources

Morgantown, WV

2020

Keywords: Perca flavescens, yellow perch, spawning, artificial habitat, Cheat Lake 


\section{Abstract \\ Spawning Characteristics of Yellow Perch during Periods of Water Level Fluctuations in a Hydropower Reservoir}

Kyle J. Matt

Water level fluctuations alter reservoir ecosystems causing direct and indirect effects on fish populations. The dewatering of eggs, a direct impact of lake level drawdowns, can affect reproductive success of species that spawn in littoral zones, such as Yellow Perch. I examined relationships between water level fluctuations and spawning characteristics of Yellow Perch in a Central Appalachian hydropower reservoir, where water levels were permitted to be drawn down to $4 \mathrm{~m}$ and $2.1 \mathrm{~m}$ below the full pool elevation in March and April, respectively. Daily presences of egg masses were recorded on artificial spawning structures at two sites for the spring spawning seasons of 2019 and 2020. Spawning structures were placed at different distances from the shoreline, spanning water depths with and without the potential for dewatering based on the lowest permitted levels for lake elevation drawdowns. Generalized Estimation Equations (GEE) were used to analyze egg mass presence and six covariates: Secchi disk depth, distance to the shore, water temperature, water depth, lunar illumination, and lake level fluctuation. I also examined the proportion of egg masses in potential dewatering zones based on the minimum lake elevation drawdowns permitted for March and April. Data supported an additive effects model of Year + Water depth + Lunar illumination + Water temperature. The predicted probability of egg mass presence was negatively associated with water depth and lunar illumination, and positively associated with water temperature. A year effect, in part, reflected a between-year difference in the timing of spawning, where the number of egg masses during April exceeded that of March in 2019, a relationship that was reversed in 2020. During the 27-day spawning period in 2019, 52\% (54 of 104) of egg masses had the potential to be dewatered, whereas $70 \%$ (30 of 43) had the potential to be dewatered in the 22-day spawning period of 2020. Our results have direct implications for fishery and hydropower management, as data on the characteristics and timing of spawning of yellow perch relative to water level fluctuations inform decisions regarding management of fish populations and lake level drawdown regulations. 


\section{ACKNOWLEDGEMENTS}

To Dr. Stuart Welsh,

I would like to thank you for being my major professor and allowing me to complete this project under your guidance. I want to thank you for your professional guidance in designing and implementing my project, as well as helping me improve my writing ability. Most of all, I want to thank you for your encouragement throughout my time in graduate school.

To my family,

I want to thank you all for your love and support during my time in graduate school. Thank you, Dad, for showing, teaching, and instilling in me over the years a good work ethic. Without you giving me this gift, I would not be where I am today. Thank you, Mom, for teaching me how to enjoy learning and giving me a passion to learn more about the world around me. Tatiana, being married to you is such a blessing. Your love, encouragement, and mastery of Excel has made my life exponentially better, and I could not have imagined completing this journey without you by my side.

To my technicians,

Thank you, Corey Tucker and Zane Sine, for your hard work. Thank you for enduring cold weather and rainy days of data collection. Without your hard work, this project would not have been possible. I enjoyed working with both of you very much. 


\section{Table of Contents}

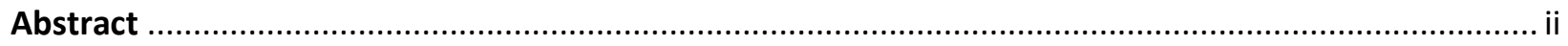

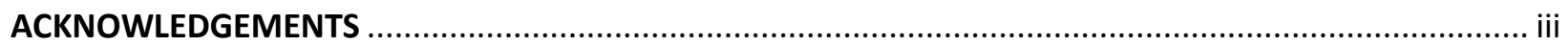

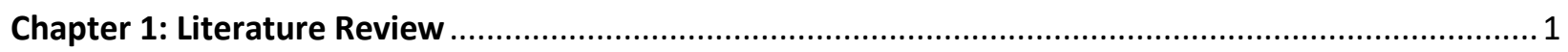

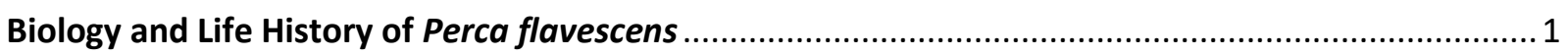

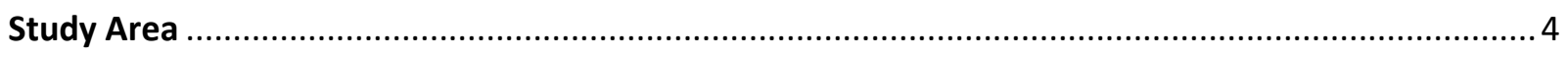

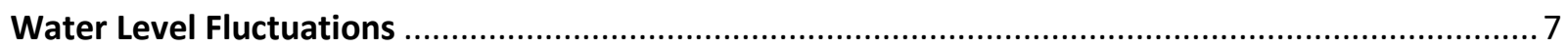

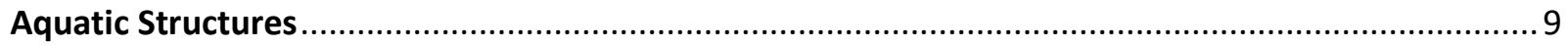

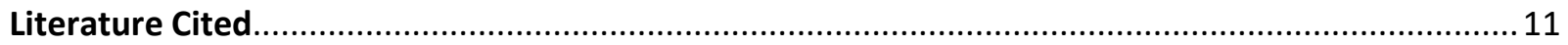

Chapter 2: Spawning Characteristics of Yellow Perch during Periods of Water Level Fluctuations in a

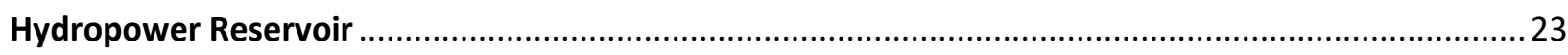

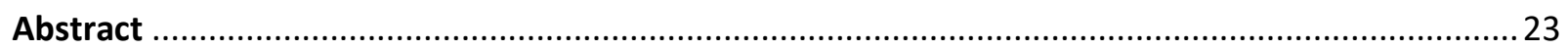

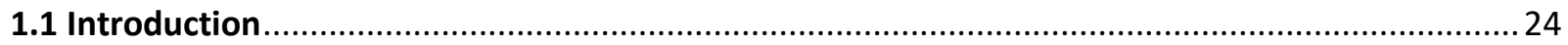

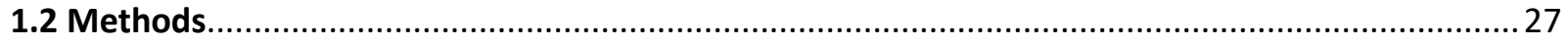

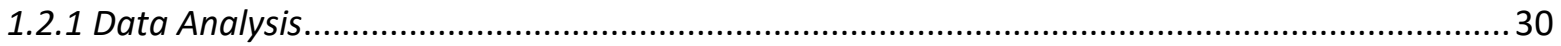

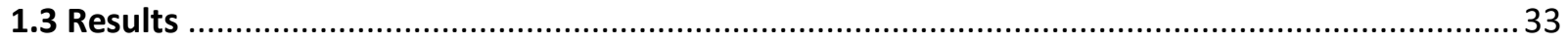

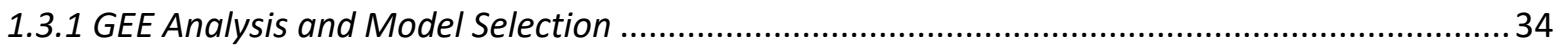

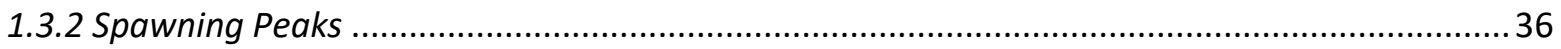

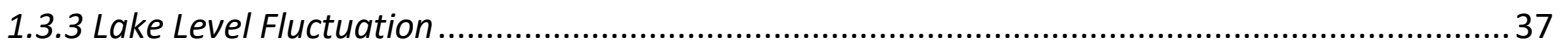

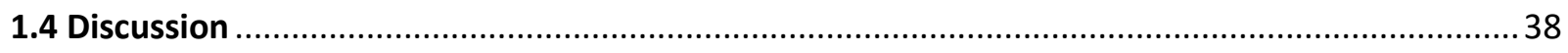

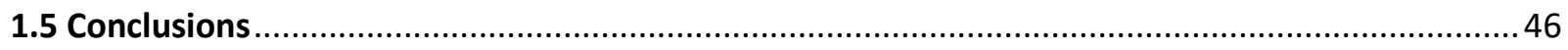

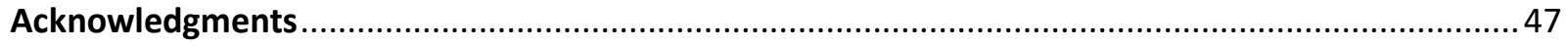

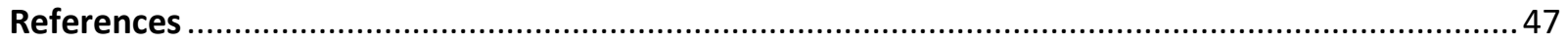




\section{List of Tables}

Table 1.1. Model selection statistics for 35 candidate models (i.e., alternative hypotheses) fit to egg mass presence/absence data from Cheat Lake, West Virginia. Models included a year effect (2019 and 2020) or site effect (Crammys Run and Canyon Bend). Covariates were water temperature (Temp), water depth (Depth), lunar illumination (Lunar), distance to shoreline (Distance), lake level fluctuation (LLF), and Secchi disk depth (Secchi).

Table 1.2. Summary statistics of habitat variables for all spawning habitat units and for those units with presence of yellow perch egg masses $(\mathrm{N}=$ sample size, $\mathrm{SE}=$ standard error, $\min =$ minimum value, and $\max =$ maximum value)

Table 1.3. Proportion of artificial spawning habitat units with and without egg masses located in areas of potential dewatering zones, as defined by minimum lake drawdown regulations. An elevated egg mass is located on structures at $1.0 \mathrm{~m}$ above the lake bottom, and a bottom egg mass is located on the lake bottom. Proportions (Estimate) are provided with lower (LCI) and upper (UCI) 95\% profile likelihood confidence intervals 


\section{List of Figures}

Fig. 1.1. Cheat Lake, located in northern West Virginia, including locations of two study sites (black stars). One site was located near the mouth of Crammys Run, and the other site was on the inside shoreline of Canyon Bend.

Fig. 1.2. Artificial spawning habitat structures used in a study of Yellow Perch on Cheat Lake, West Virginia.

Fig 1.3. Study sites at Crammys Run (top) and Canyon Bend (bottom). White buoys mark the locations of the spawning habitat units. When the water depth was less than or equal to $1.83 \mathrm{~m}(6 \mathrm{ft})$, then the white PVC floats of the spawning habitat units were on top of the water (see bottom right). An organization contact and phone number was printed on each white buoy. One large buoy at each site (see bottom left) was used to alert boaters and provide information about the research project.

Fig. 1.4. Photographs of the egg counting process, including an ethanol-preserved Yellow Perch egg mass (A), ethanol strained from a preserved egg mass (B), and partitioned subsamples of eggs (C, D)...63

Fig. 1.5. Time series of daily counts of Yellow Perch egg masses on 40 artificial habitat units. Water temperature and lunar illumination are plotted for the spawning periods, which ranged from 21 March16 April in 2019 and 21 March-11 April in 2020. Spawning peaks were determined by fitting a set of candidate mixture models to daily egg mass counts, where AIC model selection supported a 2-mixture model for 2019, and a unimodal model for 2020.

Fig. 1.6. Yellow Perch egg masses spiraled (left) or draped (right) around artificial spawning habitat structures.

Fig. 1.7. Predicted probability of egg mass presence on artificial spawning habitat based on analyses using Generalized Estimating Equations (GEE). Plots depict relationships from 2019 and 2020 of single model covariates; Secchi disk depth, lake level fluctuation, distance to shore, water temperature, lunar illumination, and water depth.

Fig. 1.8. Water depths of artificial spawning habitat units during sampling in 2019 and 2020 with and without the presence of egg masses.

Fig. 1.9. Distances from shoreline of artificial spawning habitat units with and without the presence of egg masses for 2019 and 2020. The $y$-axis is a count of habitat units. Distances were measured from the water surface (directly above submerged habitat units) to the full pool water mark on the nearest shoreline. 
Fig. 1.10. Artificial spawning habitat structures with the presence of Yellow Perch egg masses relative to lake level fluctuations in one-tenth meter increments. 69

Fig. 1.11. Amplitude, frequency, duration, and timing of fluctuations in surface elevation of Cheat Lake during February-April of 2019 and 2020. Elevation at full pool is $265.2 \mathrm{~m}$. The minimum permitted drawdown elevation is shown for February-March (261.2 m) and April (263 m). Gray zones represent spawning periods of Yellow Perch.

Fig. 1.12. Amplitude, frequency, duration, and timing of fluctuations in surface elevation of Cheat Lake during February-April of 2016-2018. Elevation at full pool is $265.2 \mathrm{~m}$. The minimum permitted drawdown elevation is shown for February-March (261.2 $\mathrm{m}$ ) and April (263 m).

Fig. 1.13. Proportion of egg masses in 2019 and 2020 with potential for dewatering at Crammys Run and Canyon Bend, Cheat Lake, West Virginia. Estimates are based on two scenarios, where egg masses are deposited directly onto the lake bottom (A), or egg masses are deposited onto structures at $1.0 \mathrm{~m}$ above the lake bottom (B). Error bars are $95 \%$ profile likelihood confidence intervals.

Fig. 1.14. Examples of lake level drawdown of Cheat Lake, West Virginia (A, B), egg masses associated with near-shore natural structure $(C, D)$, and a dewatered egg mass on a natural structure (D). 


\section{Chapter 1: Literature Review}

\section{Biology and Life History of Perca flavescens}

The Yellow Perch (Perca flavescens), a member of the Percidae family, was described by Samuel Latham Mitchill in 1814 (Jenkins and Burkhead 1993). This species has a wide geographic range that covers a large portion of North America (Page and Burr 2011). Morphological characteristics of Yellow Perch include 6-9 dark vertical bars on each side of the fish (Brown et al. 2009, Page and Burr 2011). They have two separate dorsal fins. The first dorsal fin contains 12-14 spines and the second has 1-2 spines with the rest of the fin consisting of rays (Scott and Crossman 1973; Jenkins and Burkhead 1993).

Yellow Perch range widely in both habitat use and diet, contributing to their tolerance of environmental changes. Because of these attributes, they inhabit much of North America (Jenkins and Burkhead 1993). Yellow Perch inhabit reservoirs, natural lakes, streams, and rivers. They tolerate saline water up to 5 percent (Mansueti 1964), allowing occupancy of brackish waters. Yellow Perch are opportunistic feeders consuming zooplankton, fish and benthic invertebrates (Tyson and Knight 2001). Owing in part to the Yellow Perch's generalist traits, the species was successfully introduced by the US Fish Commission into many western States in the late $19^{\text {th }}$ and early $20^{\text {th }}$ centuries (Moyle 2002).

Yellow Perch spawn annually in the spring. Two main environmental cues trigger spawning: water temperature and photoperiod (Hokanson 1997, Heidinger and Kayes 1986). Hokanson (1977) found that spawning occurred between 2.0 and $18.6^{\circ} \mathrm{C}$. Eggs incubated in 
water temperature between 8.5 and $10.0^{\circ} \mathrm{C}$ have the highest rate of gamete viability (Tsai and Gibson 1971). Spawning has been observed during late winter in southern latitudes and early summer in northern latitudes (Jenkins and Burkhead 1993). Male Yellow Perch usually reach sexual maturity earlier in life than females do (Jenkins and Burkhead 1993). Males typically reach sexual maturity in 2-3 years and females require 3-4 years (Becker 1983). Communal spawning behavior has been documented with more than 25 male Yellow Perch pursuing one female (Harrington 1947). Yellow Perch usually spawn at night (Scott and Crossman 1973).

Female Yellow Perch deposit large eggs masses, that can also be referred to as egg skeins. Egg masses have a ribbon-like appearance and are held together in a gelatinous matrix in an accordion-shape. The gelatinous matrix contains potential toxins that reduce predation on the egg mass (Almeida et al. 2017). These noxious components include piperideine and nattectin (Almeida et al. 2017). Depending on the size of a gravid female, they can carry between 2,000 and 157,600 eggs (Brazo et al. 1975, Hardy 1978), but on average egg masses usually contain between 23,316 and 25,512 (Hanchin et al. 2003), and 23,000 (Scott and Crossman 1973, Hardy 1978). These strands of eggs are usually about 1.5 inches thick (Mansueti 1964) and can be up to $2 \mathrm{~m}$ long (Herman et al. 1959). Eggs extruded from the female have a clear amber color (Mansueti 1964).

During spawning, females typically drape semi-buoyant egg masses near shore in littoral zones over aquatic vegetation or submerged woody debris (Echo 1955; Muncy 1962; Scott and Crossman 1973; Nelson and Walburg 1977; Becker 1983; Robillard and Marsden 2007). The draping action mechanically stretches the mass of eggs to allow sperm and oxygen to reach the inside folds increasing fertilization and hatching success (Regier et al. 1969; Kayes 1977). If egg 
masses are stationary and secured to rooted vegetation, then developing embryos may experience reduced physical damage (Regier et al. 1969). In the absence of spawning structure, females will deposit egg masses on sand, gravel and rubble (Herman et al. 1959; Noble 1970). This spawning method is unique relative to other North American freshwater fishes (Robillard and Marsden 2007).

The depth of egg deposition, incubation time, and hatching success can vary depending on the dissolved organic carbon (DOC) of the system and water temperature. A study by Huff et al. (2004), found that 93 percent of eggs deposited in a low-DOC system were in depths of $3 \mathrm{~m}$ or greater, while 76 percent of eggs were deposited in water less than $1 \mathrm{~m}$ deep in the highDOC system. This difference in spawning depth is due to the protection DOC gives the eggs from ultraviolet radiation (Huff et al. 2004). Huff et al. (2004) found that 100 percent of eggs died before hatching in shallow waters in the low-DOC lake. Higher water temperatures found in shallower water can lead to quicker egg development. Huff et al. (2004) recorded that eggs deposited in warmer, shallower, surface waters developed 10-26 days faster than eggs deposited in cooler deeper waters. Both DOC and water temperature play an important role determining the success of eggs deposited within a system.

Eggs go through several stages following fertilization with incubation time varying by location. A study by Mansueti (1964) found the mean egg diameter after fertilization and before water-hardening to be $1.76 \mathrm{~mm}$. Within a few minutes directly after fertilization, waterhardening occurs, and the eggs swell to a size between 1.87 to $2.81 \mathrm{~mm}$ (Mansueti 1964). There is much variation in incubation time of the eggs. A study at Lake Itasca, Minnesota, found eggs hatched 10-20 days after spawning occurred (Whiteside et al. 1985). Mansueti (1964) observed 
eggs hatching 25 to 27 days after fertilizations. An additional study in Canada found incubation to last between 8 to 10 days (Roberge et al. 2001).

Shifts in diet occur during the larval and post-larval stages. Upon hatching, larval fish are between 5.5 and $6 \mathrm{~mm}$ in length (Mansueti 1964). Until the Yellow Perch reach approximately 9 $\mathrm{mm}$ in length, they are endogenous feeders (Whiteside et al. 1985). Once the larval fish move into the limnetic habitat, they start to consume copepods, and shortly after, they start consuming cladocera and occasionally rotifers (Whiteside et al. 1985). Larvae remain in the limnetic zone for about 30-40 days, then migrate back into the littoral habitat where their diet shifts to larger prey dwelling in the substrate, such as amphipods and aquatic insects (Whiteside et al. 1985). Aquatic vegetation is commonly found in littoral areas, which provides cover for young Yellow Perch (Herman et al. 1959; Ward and Robinson 1974; Kitchell et al. 1977; Helfman 1979).

\section{Study Area}

Cheat Lake is a hydropower impoundment on Cheat River. The lake is located 6 km NE of Morgantown, WV. The dam is located on the North end of the lake, near the West VirginiaPennsylvania border. The surface area of the lake is 700 hectares (1730 acres), with a length of $20.9 \mathrm{~km}$ and ranges from 0.8-1.2 km in width (Schwartz 1991). Cheat Lake provides many outdoor recreation activities such as boating, fishing and birdwatching. There are many different fisheries for both bank and boat anglers, which include black bass Micropterus spp., crappie Pomoxis spp., Channel Catfish Ictalurus punctatus, Bluegill Lepomis macrochirus and Pumpkinseed sunfish Lepomis gibbosus, Walleye Sander vitreus, White Bass Morone chrysops, 
and Yellow Perch. The fisheries of Cheat Lake are managed by the West Virginia Division of Natural Resources (WVDNR). The regulations are set, in part, by fishery dependent and fishery independent data. Since Cheat Lake is a hydropower impoundment, the water is often drawn down to create electricity through the hydropower production process. These drawdowns influence the management decisions of the fishery.

Cheat Lake was affected by acid mine drainage (AMD) for much of its past, but recently has experienced improvements in water quality. Within the Cheat River watershed, there have been many retired coal mines that have fed acidic water into Cheat Lake. During an aquatic plant survey in the fall of 1969, a pH ranging from 4.0 to 5.5 was found at 17 different sample sites on Cheat Lake (Clovis 1971). Corbett (1977) showed that some of Cheat Lake's direct tributaries had a pH of less than 3.0. Since 2004, the water $\mathrm{pH}$ entering the lake usually remains above 6.0 (Jernejcic and Wellman 2011).

Cheat Lake's fisheries have improved, owing in part to AMD remediation and increased water quality. In the 1950s, only 15 fish species were recorded in the lake (Jernejcic and Wellman 2011). In 1990, there were 33 fish species recorded at Cheat Lake (Jernejcic and Wellman 2011). American Rivers ranked Cheat River as the $8^{\text {th }}$ most endangered river in North America, because of the effects of AMD in the lower section of the river (Williams et al. 1999). A review of fish sampling data from 1990-2015 revealed 44 fish species in the lake (Smith 2018). Both game fish and forage fish species have increased since the 1990 study (Jernejcic and Wellman 2011). 
A population assessment was conducted previously on Yellow Perch in Cheat Lake.

Research by a West Virginia University graduate student evaluated age and length, summer diet composition, and growth data. A total of 271 Yellow Perch were collected ranging in size from 66-320 mm; the maximum age was estimated to be 9 years (Taylor 2013). Taylor (2013) found that females grew faster and reached larger maximum sizes than males. An ontogenetic diet shift was observed (Taylor 2013).

The water levels of Cheat Lake have varied since the lake was formed. In the 1920s, there were no flow regulations mandated by state or federal agencies (Jernejcic and Wellman 2011). This changed in 1994, when the Allegheny Energy Supply Company entered a new license agreement with The Federal Energy Regulatory Commission (FERC; Jernejcic and Wellman 2011). The FERC permit requires the hydropower project to support fish populations. This new agreement set lake elevations throughout the year and required a minimum discharge year-round. The minimum discharge from the dam was instituted to improve conditions downstream by mitigating the influence of acid tributaries (Smith and Welsh 2015). From May

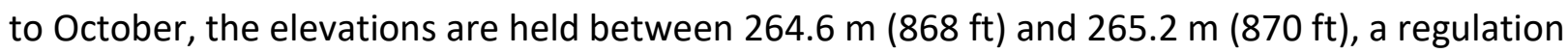
that enhances recreational activities. From November through March, the lake fluctuates between $261.2 \mathrm{~m}(857 \mathrm{ft})$ and $265.2 \mathrm{~m}(870 \mathrm{ft})$. In April, the elevation fluctuates between 263 $(863 \mathrm{ft})$ and $265.2 \mathrm{~m}$ (870 ft), a regulation to reduce impacts on early spawning fishes, specifically Yellow Perch and Walleye. 


\section{Water Level Fluctuations}

The impact of water level fluctuations on aquatic species has been studied for decades. Many of these studies have taken place on rivers that are dammed for hydropower and floodcontrol purposes (Hecky et al. 1984; Rosenberg et al. 1987; Avakyan and Podol'skii 2002). Anthropogenic water level fluctuations have been shown to reduce fish abundance (Gaboury and Patalas 1984). The effect of water level fluctuations can vary depending on the magnitude, duration and timing, and species exposed (Cott et al. 2008). Extreme water level fluctuations can surpass the physiological and behavioral adaptability of species that occupy these systems (Coops et al. 2003). Many species use shallow littoral areas for spawning, rearing and feeding. Littoral areas are often the first affected by water level fluctuations. Lake level drawdowns can dewater littoral areas causing negative effects on year class recruitment (Groen and Schroeder 1978). To help reduce the negative impact of water level fluctuations, large changes to water levels should be avoided during normally stable times, including mid-summer and winter (Cott et al. 2008). Water level fluctuations can affect lentic systems in many ways, such as changes in the availability of foraging and spawning habitats, the amount of light reaching certain areas of the lake, and wave impact (Wantzen et. al. 2008).

Water level fluctuations have been associated with alterations of movement patterns, growth rates, and survival rates (Cott et al. 2008), as well as competitive displacement of aquatic organisms (Hunt and Jones 1972). Regarding fish distribution, Largemouth Bass (Micropterus salmoides) and Northern Pike (Esox lucius) may alter movements due to water level drawdowns (Rogers and Bergerson 1995). Young of the year Largemouth Bass experienced lower survival rates because of water level fluctuations in a Tennessee reservoir (Sammons et 
al. 1999). A decrease in numbers of Yellow Perch and a reduced growth rate have been associated with water level fluctuations (Gaeta et al. 2014). Smallmouth Bass Micropterus dolomieu have been recorded abandoning nests during water level fluctuations, with egg survival decreasing when the magnitude of fluctuation is increasing (Clark et al. 2008). The natural dispersion of young fish can be changed by increasing or limiting flow (Bonetto et al. 1989). Fischer and Ohl (2005) showed that juvenile Burbot Lota lota were displaced by larger fish during water level drawdowns.

The bathymetry of aquatic systems can determine effects of water level changes on fish populations. Zohary and Ostrovsky (2011) defined deep lakes as those that stratify seasonally. The impact of water fluctuation is not usually as noticeable in deep lakes as compared to shallow systems (Nowlin et al. 2004). Even if impacts from water fluctuation are not as noticeable in deeper systems, these fluctuations can affect certain fish species (Alexander 1986; Jansen 2000; Rose 2005). Some of the most affected fish species are those like Yellow Perch, which lay adhering eggs (Fisher et al. 1996, Zohary and Ostrovsky 2011). As previously discussed, Yellow Perch drape egg skeins on woody debris and vegetation in littoral zones (Echo 1955, Muncy 1962, Scott and Crossman 1973, Nelson and Walburg 1977, Becker 1983). Water level drawdowns can reduce availability of spawning structures. Egg masses have been observed being dewatered during drawdowns in Cheat Lake (Hilling et al. 2018) Gaeta et al. (2014) found that water level reductions exceeding $1.1 \mathrm{~m}$ reduced up to $76 \%$ of the available submerged woody debris.

Water level fluctuations can impact aquatic invertebrates (Hunt and Jones 1972; Benson and Hudson 1975), which are important dietary items for juveniles and adults of many fishes. 
Water level fluctuations, depending on magnitude and duration, have variable effects on macroinvertebrate communities (Furey et al. 2006). White et al. (2011) found that communities of macroinvertebrates were similar between natural lakes and reservoirs, until the fluctuations exceeded $1.5 \mathrm{~m}$. White et al. (2011) also documented that species richness declined when the fluctuations exceeded $2.0 \mathrm{~m}$. The decline of species richness may have negative consequences for macroinvertebrate communities, as well as for fish populations.

Water level fluctuations impact aquatic plant communities (Rørslett 1989; Hellsten et al. 1996; Hudon 2004; Turner et al. 2005), which provide food and cover for aquatic invertebrates and fishes. In some cases, water level fluctuations have been used to manage or control aquatic vegetation (Tarver 1980) and improve fisheries (Heman et al. 1996). Water level fluctuations are also used to increase aquatic vegetation. This can be accomplished by having low-water during the re-vegetation season and then high-water during the nursery season (Fisher and Zale 1991). In some cases, water level changes provide a cost-efficient control of some aquatic vegetation over chemical means (Lantz et al. 1967). In one study, water level fluctuation successfully reduced $95 \%$ of noxious weeds and sport fish harvest increased by $250 \%$ (Lantz et al. 1967).

\section{Aquatic Structures}

Artificial structures have been used in the United States for almost a century to modify aquatic habitats and enhance fisheries (Bolding et al. 2004). There are many different types of natural or artificial structures a manager can add to a system. These structures could be relatively simple, such as the piling of trees, brush and rocks, or more complex with a series of 
habitats in the form of a reef. Alternatively, artificial structures have been used, such as spider blocks, PVC structures, corrugated plastic pipe, snow fencing, and aluminum siding.

An expected benefit of using habitat structures is the improvement of fisheries. Artificial structures may increase spawning habitat, provide cover that increases the survival of small fishes, and ultimately increase angler catch per effort (Bolding et al. 2004). An increased abundance of Largemouth Bass, Bluegill, and crappies have been associated with habitat structures (Johnson et al. 1988; Lynch and Johnson 1989; Johnson and Lynch 1992; Allen et al. 2014; Daugherty et al. 2014; Baumann et al. 2016).

Artificial habitat can play an important role in homogenous systems that lack fish habitat, such as many older reservoirs in the U.S. Reservoirs often lack structure owing to local logging and commercial development, where the amount of woody debris entering the system has been reduced. Even if the area surrounding a reservoir is second-growth forest, there may not be enough course woody debris available for adequate structure. In 2016, the median age of U.S. reservoirs was 66 years (Miranda 2017). The functional age of reservoirs varies on several factors, two of which are the depth of the reservoir and the amount of agricultural runoff and effluents (Miranda 2017). To counteract the decrease in productivity, managers can add structures to the system. The percent of agencies that add structures to aquatic systems has increased from 62\% in 1978 (Prince and Maughan 1978) to more than 80\% in 1999 (Baumann et al. 2016).

This introductory chapter provides a literature review in support of the second chapter of this thesis. Chapter 2 is a manuscript of my thesis research study which focuses on the 
spawning characteristics of Yellow Perch in Cheat Lake, with an emphasis on water level fluctuation and its role in the potential for egg dewatering. Factors that influence spawning success, such as water level fluctuations, likely contribute to variable recruitment, which is a common management issue for Yellow Perch (Ridenhour 1960, Koonce et al. 1977, Craig and Kipling 1983, Newsome and Alto 1987). Thus, the results of this research study have management implications, as data will inform decisions regarding fish populations and lake level drawdown regulations.

\section{Literature Cited}

Allen, M. J., S. C. Busch, I. Vining, and M. J. Siepker. 2014. Black bass and crappie use of installed habitat structures in Table Rock Lake, Missouri. North American Journal of Fisheries Management 34:223-231.

Alexander, C. M. 1986. Impact assessment of extreme drawdown on the Watauga Reservoir fishery. Proceedings of the Annual Conference of the Southeastern Association of Fish and Wildlife Agencies 40:15-26.

Almeida L. Z., G. C. Samuel, T. A. Krieg, and T. O. Höök. 2017. Predators reject yellow perch egg skeins. Transactions of the American Fisheries Society 146:173-180.

Avakyan, A. B., and S. A. Podol'skii, 2002. Impact of reservoirs on the fauna. Water Resources 29:123-132. 
Baumann, R. J., N. C., Oakley, and B. J., Mcrae. 2016. Evaluating the effectiveness of artificial fish habitat designs in turbid reservoirs using sonar imagery. North American Journal of Fisheries Management 36:1437-1444.

Becker, G. C. 1983. Fishes of Wisconsin. University of Wisconsin Press, Madison.

Benson, N. G., and P. L. Hudson. 1975. Effects of a reduced fall drawdown on benthos abundance in Lake Francis Case. Transactions of the American Fisheries Society 3:526528.

Bolding, B., S. Bonar, and M. Divens. 2004. Use of artificial structures to enhance angler benefits in lake, ponds, and reservoirs: a literature review. Reviews in Fisheries Science 12:7596.

Bonetto, A. A., J. R. Wais, and H.P. Castello. 1989. The increasing damming of the Parana Basin and its effects on the lower reaches. Regulated Rivers Research and Management $4: 333-346$.

Brazo D. C., P. I. Tack, and C. R. Liston. 1975. Age, growth, and fecundity of yellow perch, Perca flavescens, in Lake Michigan near Ludington, Michigan. Transactions of the American Fisheries Society 104:726-730.

Brown, T., B. Runciman, M. Bradford, and S. Pollard. 2009. A biological synopsis of yellow perch (Percina flavescens). Canadian Manuscript Report of Fisheries and Aquatic Science 2883: $\mathrm{v}-28$. 
Clark, M. E., K. A. Rose, J. A. Chandler, T. J. Richter, D. J. Orth, and W. Van Winkle. 2008. Waterlevel fluctuation effects on centrarchid reproductive success in reservoirs: a modeling analysis. North American Journal of Fisheries Management 28:1138-1156.

Clovis, J. F. 1971. Aquatic vascular plant distribution in Cheat Lake (Lake Lynn), West Virginia. Castanea 36:153-163.

Coops, H., M. Beklioglu, and T.L. Crisman. 2003. The role of water-level fluctuations in shallow lake ecosystems - Workshop Conclusions. Hydrobiologia 506-509:23-27.

Corbett, R. G. 1977. Effects of coal mining on ground and surface water quality, Monongalia County, West Virginia. The Science of the Total Environment 8:21-38.

Cott, P. A., P. K. Sibley, W. M. Somers, M. R. Lilly, and A. M. Gordon. 2008. A review of water level fluctuations on aquatic biota with an emphasis on fishes in ice-covered lakes. Journal of the American Water Resources Association 44:343-359.

Craig, J. F. and C. Kipling. 1983. Reproduction effort versus the environment: case histories of Windennere perch, Perca fluviatilis L., and pike, Esox lucius L. Journal of Fish Biology $22: 713-727$.

Daugherty, D. J., M. T. Driscoll, D. E. Ashe, and J.W. Schlechte. 2014. Effects of structural and spatiotemporal factors on fish use of artificial habitat in a Texas reservoir. North American Journal of Fisheries Management 34:453-462.

Echo, J. B. 1955. Some ecological relationships between yellow perch and trout in Thompson Lake, Montana. Transactions of the American Fisheries Society 84:239-248. 
Furey, P. C., R. N. Nordin, and A. Mazumder. 2006. Littoral benthic macroinvertebrates under contrasting drawdown in a reservoir and a natural lake. Journal of the North American Benthological Society 25:19-31.

Fischer, P. and U. Ohl. 2005. Effects of water-level fluctuations on the littoral benthic fish community in lakes: a mesocosm experiment. Behavioral Ecology 16:741-746.

Fisher, S. J., K. L. Pope, L. J. Templeton, and D. W. Willis. 1996. Yellow perch spawning habitats in Pickerel Lake, South Dakota. Prairie National 28:65-75.

Fisher, W. L. and A. V. Zale. 1991. Effect of water level fluctuations on abundance of young-of year largemouth bass in a hydropower reservoir. Proceedings of the Annual Conference Southeastern Association of Fish and Wildlife Agencies 45:422-431.

Gaboury, M. N. and J. W. Patalas. 1984. Influence of water level drawdown on the fish populations of Cross Lake, Manitoba. Canadian Journal of Fisheries and Aquatic Sciences 41:118-125.

Gaeta, J. W., G. G. Sass, and S. R. Carpenter. 2014. Drought-driven lake level decline: effects on coarse woody habitat and fishes. Canadian Journal of Fisheries and Aquatic Sciences 71:315-325.

Groen, C. L., and T. A. Schroeder. 1978. Effects of water level management on walleye and other coolwater fishes in Kansas reservoirs. American Fisheries Society Special Publication 11:278-283. 
Hanchin, P. A., D. W. Willis, and T. R. St. Sauver. 2003. Influence of introduced spawning habitat on yellow perch reproduction in Lake Madison, South Dakota. Journal of Freshwater Ecology 18:291-297.

Hardy Jr. J. D. 1978. Development of fishes of the Mid-Atlantic Bight. An atlas of egg, larval, and juvenile stages, Volume III US Fish and Wildlife Service, Biological Services Program FWSOBS-78/12.

Harrington, R. W., Jr. 1947. Observations on the breeding habits of the yellow perch, Perca flavescens (Mitchill). Copeia 1947:199-200.

Hecky, R. E., R. W. Newbury, R. A. Bodaly, K. Patalas, and D.M. Rosenberg. 1984. Environmental impact prediction and assessment: The Southern Indian Lake experience. Canadian Journal of Fisheries and Aquatic Sciences 41:720-732.

Helfman, G. S. 1979. Twilight activities of yellow perch, (Perca flavescens). Journal of the Fisheries Resource Board Canada 36:173-179.

Heidinger, R. C., and T. B. Kayes. 1986. Culture of Nonsalmonid Freshwater Fishes. Pages 104114 in R. R. Stickney, editor. Yellow perch. CRC Press, Boca Raton, Florida.

Hellsten, S., M. Marttunen, R. Palomaki, J. Riihimaki, and E. Alasaarela, 1996. Towards an ecologically based regulation practice in Finnish hydroelectric lakes. Regulated Rivers: Research and Management 12:535-545. 
Herman, E., W. Wisbey, L. Wiegert, and M. Burdick. 1959. The yellow perch: Its life history, ecology, and management. Wisconsin Conservation Department Publication 228. Madison, Wisconsin.

Heman, M. L., R. S. Campbell, and L. C. Redmond. 1969. Manipulation of fish populations through reservoir drawdown. Transactions of the American Fisheries Society 98:293304.

Hilling C. D., N. D. Taylor, S. A. Welsh, and D. M. Smith. 2018. Population characteristics of Yellow Perch in a central Appalachia hydropower reservoir. Journal of Fish and Wildlife Management 9:475-484.

Hokanson, K. E. F. 1997. Temperature requirements of some percids and adaptations to the seasonal temperature cycle. Journal of the Fisheries Research Board of Canada 34: 1524-1550.

Hudon, C. 2004. Shift in wetland plant composition and biomass following low-level episodes in the St. Lawrence River: looking into the future. Canadian Journal of Fisheries and Aquatic Sciences 61:603-617.

Huff, D. D., G. Grad, and C. E. Williamson. 2004. Environmental constraints on spawning depth of yellow perch: The roles of low temperature and high solar ultraviolet radiation. Transactions of the American Fisheries Society 133:718-726.

Hunt, P. C., and J. W. Jones. 1972. The effect of water level fluctuations on littoral fauna. Journal Fish Biology 4:385-394. 
Jansen, W. 2000. Experimental Drawdown of Lake 226 in the Experimental Lakes Area, Ontario: Implications for Fish Habitat Management in Lakes and Reservoirs with Fluctuating Water Levels. Prepared for Department of Fisheries and Oceans, Central and Arctic Region, Winnipeg, March 11, 2000. 29 pp + appendices.

Jenkins, R. E., and N. M. Burkhead. 1993. Freshwater Fishes of Virginia. American Fisheries Society, Bethesda, Maryland.

Jernejcic, F., and D. Wellman. 2011. The recovery of Cheat Lake: A success story. West Virginia Wildlife 1:2-6.

Johnson, D. L., R. A. Beaumier, and W. E. Lynch Jr. 1988. Selection of habitat structure interstice size by Bluegills and Largemouth Bass in ponds. Transaction of the American Fisheries Society 117:171-179.

Johnson, D. L., and W. E. Lynch. 1992. Panfish use of and angler success at evergreen tree, brush and stake-bed structures. North American Journal of Fisheries Management 12:222229.

Kayes, T. 1977. Reproductive biology and artificial propagation methods for adult perch. Pages 6-23 in R.W. Soderberg, editor. Perch fingerling production for aquaculture. University of Wisconsin Sea Grant College Program Advisory Report 42-1, Madison.

Kitchell, J. F., M. G. Johnson, C. K. Minns, K. H. Loftus, L. Greig, and C. M. Oliver. 1977. Percid habitat: The river analogy. Journal of Fisheries Resources Board Canada 34:1936-1940. 
Koonce, J. F., T. B. Bagenal, R. F. Carline, K. E. F. Hokanson, and M. Nagiec. 1977. Factors influencing year-class strength of percids: a summary and a model of temperature effects. Journal of the Fisheries Research Board of Canada 34:1900-1909.

Lantz, K. E., J. T. Davis, J. S. Hughes, and J. E. Schafer. 1967. Water level fluctuation - its effects on vegetation control and fish population management. Proceedings of the Annual Conference Southeastern Association of Game and Fish Commissioners 18:483-494.

Lynch, W. E., Jr., and D. L. Johnson. 1989. Influences of interstice size, shade, and predators on the use of artificial structures by bluegills. North American Journal of Fisheries Management 9:219-225.

Mansueti, A. J. 1964. Early development of the yellow perch, Perca flavescens. Chesapeake Science 5:46-66.

Miranda, L. E. 2017. Reservoir Fish Habitat Management. Lightning Press, Totowa, New Jersey.

Moyle, P. B. 2002. Inland Fishes of California. University of California Press, Berkley.

Muncy, R. J. 1962. Life history of the yellow perch, Perca flavescens, in estuarine waters of the Severn River, a tributary of Chesapeake Bay. Chesapeake Science 3:142-159.

Nelson, W. R., and C. H. Walburg. 1977. Population dynamics of yellow perch (Perca flavescens), sauger (Stizostedion canadense), and walleye (S. vitreum vitreum) in four main stem Missouri river reservoirs. Journal of the Fisheries Research Board of Canada 34:17481763. 
Newsome, G. E., and S. K. Aalto. 1987. An egg-mass census method for tracking fluctuations in yellow perch Perca flavescens populations. Canadian Journal of Fisheries and Aquatic Sciences 44:1221-1232.

Noble, R. L. 1970. Evaluation of the Miller high-speed sampler for sampling yellow perch and walleye fry. Journal of the Fisheries Research Board of Canada 27:1033-1044.

Nowlin, W. H., J. M. Davies, R. N. Nordin, and A. Mazumder. 2004. Effects of water level fluctuation and short-term climate variation on thermal and stratification regimes of a British Columbia reservoir and lake. Lake and Reservoir Management 20:91-109.

Page, L. M., and B. M. Burr. 2011. Peterson Field Guide to Fresh Water Fishes of North America North of Mexico, Second Edition. Houghton Mifflin Harcourt, Boston, New York.

Prince, E. D. and O. E. Maughan. 1978. Freshwater artificial reefs: biology and economics. Fisheries 3:5-9.

Regier, H. A., V. C. Applegate and R. A. Ryder. 1969. The ecology and management of the walleye in western Lake Erie. Great Lakes Fisheries Commission Technical Report 15, Ann Arbor, Michigan.

Roberge, M., T. Slaney, and C. Minns. 2001. Life history characteristics of freshwater fishes occurring in British Columbia, with major emphasis on lake habitat characteristics. Canadian Manuscript Report of Fisheries and Aquatic Sciences 2574. 
Robillard, S. R., and E. J. Marsden. 2007. Spawning substrate of yellow perch along a sandcobble shoreline in southwestern Lake Michigan. North American Journal of Fisheries Management 21:208-215.

Rogers, K. B. and E. P. Bergersen. 1995. Effects of a fall drawdown on movement of adult northern pike and largemouth bass. North American Journal of Fisheries Management 15:596-600.

Rørslett, B. 1989. An integrated approach to hydropower impact assessment. Hydrobiologia 175:65-82.

Rose, C. A. 2005. Economic growth as a threat to fish conservation in Canada. Fisheries 30:3638.

Rosenberg, D. M., R. A. Bodaly, R. E. Hecky, and R. W. Newbury. 1987. The environmental assessment of hydroelectric impoundments and diversions in Canada. Canadian Bulletin of Fisheries and Aquatic Sciences 215:71-104.

Ridenhour, R. L. 1960. Abundance, growth and food of young game fish in Clear Lake, lowa, 1949 to 1957. Iowa State Journal of Science 35:1-23.

Sammons, M. S., L. G. Dorsey, P. W. Bettoli, and F. C. Fiss. 1999. Effects of reservoir hydrology on reproduction by largemouth bass and spotted bass in Normandy Reservoir, Tennessee. North American Journal of Fisheries Management 19:78-88. 
Schwartz, F. J. 1991. Depth and storage capacity changes in Cheat Lake, West Virginia, during the 64-year period 1926-1990. The Journal of the Elisha Mitchell Scientific Society 107:115-122.

Scott, W. B., and E. J. Crossman. 1973. Freshwater fishes of Canada. Fisheries Research Board of Canada Bulletin 184

Smith D., and S. Welsh. 2015. Biological monitoring of aquatic communities of Cheat Lake, and Cheat River downstream of the Lake Lynn Hydro Station. 2011-2015 FERC project number 2459.

Smith, D. M. 2018. Evaluation of a re-established walleye population within a hydropower reservoir recovering from acidification. Doctoral dissertation, West Virginia University, Morgantown.

Tarver, D. P. 1980. Water fluctuation and the aquatic flora of Lake Miccosukee. Journal of Aquatic Plant Management 18:1923.

Taylor, N. 2013. Assessment of Age, Diet, and Growth of Yellow Perch ( Perca flavescens) in Cheat Lake, West Virginia. Thesis dissertation, West Virginia University, Morgantown.

Turner, M. A., D. B. Huebert, D.L. Findlay, L.L. Hendzel, W.A. Jansen, R.A. Bodaly, L.M. Armstrong, and S.E.M. Kasian. 2005. Divergent impacts of experimental lake-level drawdown on planktonic and benthic plant communities in a Boreal Forest lake. Canadian Journal of Fisheries and Aquatic Sciences 62:991-1003. 
Tsai, C. F., and G. R. Gibson. 1971. Fecundity of the yellow perch, Perca flavescens Mitchill, in the Patuxent River, Maryland. Chesapeake Science 12:270-284.

Tyson, T. J., and R. L. Knight. 2001. Response of yellow perch to changes in the benthic invertebrate community of western Lake Erie. Transactions of the American Fisheries Society 130:766-782.

Wantzen, K. M., K. Rothhaupt, M. Mortl, M. Cantonati, L. Toth, and P. Fischer. 2008. Ecological effects of water-level fluctuations in lakes: an urgent issue. Hydrobiologia 613:1-4.

Ward, J. F., and G. G. C. Robinson. 1974. A review of research on the limnology of West Blue Lake, Manitoba. Journal Fisheries Resources Board Canada 31:977-1005.

Whiteside, M. C., M. C. Swindoll, and W. L. Doolittle. 1985. Factors affecting the early life history of yellow perch, Perca flavescens. Environmental Biology of Fishes 12:47-56.

Williams, D. R., M. E. Clark, and J.B. Brown. 1999. Stream water quality in coal mined areas of the lower Cheat River Basin, West Virginia and Pennsylvania, during low-flow conditions, July 1997. U.S. Geological Survey. Water-Resources Investigations Report 98-4258.

White, M. S., M. A. Xenopoulos, R. A. Metcalfe, and K. M. Somers. 2011. Water level thresholds of benthic macroinvertebrate richness, structure, and function of boreal lake stony littoral habitats. Canadian Journal of Fisheries and Aquatic Sciences 68:1695-1704.

Zohary T., and I. Ostrovsky. 2011. Ecological impacts of excessive water level fluctuations in stratified freshwater lakes. Inland Waters 1:47-59. 


\section{Chapter 2: Spawning Characteristics of Yellow Perch during Periods of Water Level Fluctuations in a Hydropower Reservoir}

Chapter $\mathbf{2}$ is formatted as a book chapter for publication by Springer

Abstract Water level fluctuations alter reservoir ecosystems causing direct and indirect effects on fish populations. The dewatering of eggs, a direct impact of lake level drawdowns, can affect reproductive success of species that spawn in littoral zones, such as Yellow Perch. We examined relationships between water level fluctuations and spawning characteristics of Yellow Perch in a Central Appalachian hydropower reservoir, where water levels were permitted to be drawn down to $4 \mathrm{~m}$ and $2.1 \mathrm{~m}$ below the full pool elevation in March and April, respectively. Daily presences of egg masses were recorded on artificial spawning structures at two sites for the spring spawning seasons of 2019 and 2020. Spawning structures were placed at different distances from the shoreline, spanning water depths with and without the potential for dewatering based on the lowest permitted levels for lake elevation drawdowns. Generalized Estimation Equations (GEE) were used to analyze egg mass presence and six covariates: Secchi disk depth, distance to the shore, water temperature, water depth, lunar illumination, and lake level fluctuation. We also examined the proportion of egg masses in potential dewatering zones based on the minimum lake elevation drawdowns permitted for March and April. Data supported an additive effects model of year + water depth + lunar illumination + water temperature. The predicted probability of egg mass presence was negatively associated with water depth and lunar illumination, and positively associated with water temperature. A year effect, in part, reflected a 
between-year difference in the timing of spawning, where the number of egg masses during April exceeded that of March in 2019, a relationship that was reversed in 2020. During the 27-day spawning period in $2019,52 \%$ (54 of 104) of egg masses had the potential to be dewatered, whereas $70 \%$ ( 30 of 43 ) had the potential to be dewatered in the 22-day spawning period of 2020. Our results have direct implications for fishery and hydropower management, as data on the characteristics and timing of spawning of Yellow Perch relative to water level fluctuations inform decisions regarding management of fish populations and lake level drawdown regulations.

Keywords Perca $\bullet$ Eggs $\bullet$ Spawning habitat $\bullet$ Reservoir $\bullet$ Water fluctuation $\bullet$ Hydropower

\subsection{Introduction}

Water level fluctuations in reservoirs, which can vary in amplitude, frequency, duration, and timing, result from climate-induced controls on regional precipitation, or from planned drawdowns, such as in hydropower reservoirs (Wright and Szluha 1980; Leira and Cantonati 2008; Hirsch et al. 2017). Drawdowns dewater near-shore littoral areas, reducing available habitat complexity such as riparian-contributed woody structure and aquatic vegetation (Gaboury and Patalas 1984; Zohany and Ostrovsky 2011; Gaeta et al. 2014). This loss of nearshore structure homogenizes habitat, forcing fish to find foraging and resting habitats elsewhere (Logez et al. 2016). Drawdown-induced habitat losses also have trophic level consequences that indirectly impact fish populations. For example, drawdowns reduce available forage by decreasing vegetation and primary production (Ploskey 1986, Wilcox and Meeker 1991, Hill et al. 
1998), and by reducing invertebrate population sizes (Ploskey 1986, Aroviita and Hämäläinen 2008, McEwen and Butler 2010, White et al. 2011). Moreover, a common management concern is the direct effect of drawdowns on fish reproductive success (Clark et al. 2008, de Lima et al. 2017). During periods of lake-level drawdowns, fishes that spawn in littoral zones may experience loss of spawning habitat, or post-spawn dewatering of eggs (Wahlburg 1976, Ploskey 1983; Gaboury and Patalas 1984; Gasith and Gafny 1990; Hirsch et al. 2017). At the fish assemblage level, reduced spawning success of one or more fish species leads to lower numbers of fish larvae and young-of-year fish, resulting in a reduced forage base for piscivorous fishes (Forney 1974; Pierce et al. 2006).

Cheat Lake, a 700-hectare hydropower reservoir on the Cheat River in northern West Virginia, experiences water level fluctuations resulting in part from the storage and release of water for electric power production. Lake water surface elevation at full pool is $265.2 \mathrm{~m}$ above sea level (asl). Three regulation periods are in place to limit the extent of lake drawdown below the full pool elevation. From May through October, lake elevation is relatively constant with a permitted fluctuation of $0.6 \mathrm{~m}$ between full pool ( $265.2 \mathrm{~m}$ asl) and $264.6 \mathrm{~m}$ asl. Lake elevation is permitted to be lowered $4.0 \mathrm{~m}$ below full pool $(265.2 \mathrm{~m}$ asl) to the minimum level of $261.2 \mathrm{~m}$ asl from November through March. During April, lake elevation can be drawn down $2.1 \mathrm{~m}$ below full pool (265.2 $\mathrm{m}$ asl) to a level of $263 \mathrm{~m}$ asl. Water level fluctuations during spring months may result in egg-dewatering and spawning failure for individuals of some species, such as Yellow Perch. Cheat Lake currently supports a Yellow Perch fishery, so it is relevant from a management perspective to understand the potential of population impacts owing to water level fluctuations (Taylor 2013; Smith and Welsh 2015; Hilling et al. 2018). 
The reproductive ecology of Yellow Perch is generally well-understood, but researchers have emphasized year-to-year variation in reproductive characteristics within and among water bodies (Weber and Les 1982; Krieger et al. 1983; Sztramko and Teleki 1997). Egg masses are long, transparent, gelatinous, ribbon-like, and accordion-shaped. A gravid female may have from 2,000 to 157,600 eggs depending on body size and age (Brazo et al. 1975; Hardy 1978), but average estimates of the number of eggs within an egg mass range from 23,000-35,400 (Herman et al. 1959; Hardy 1978; Hanchin et al. 2003; Weber and Les 1982). Spawning periods have been reported to range from 7-22 days (Weber and Les 1982) to > 9 weeks (Fitzgerald et al. 2001). Yellow Perch typically spawn in the shallow waters of nearshore littoral zones, where egg masses are draped across vegetation or woody debris (Echo 1955; Muncy 1962; Scott and Crossman 1973; Nelson and Walburg 1977; Becker 1983). In the absence of spawning structures, egg masses are deposited onto lake bottom substrates (Noble 1970; Smith 1986; Robillard and Marsden 2001). Water depths at spawning locations range from 0.4-2.1 m (Weber and Les 1982), 1.5-3.0 m (Herman et al. 1959), 1.0-3.7 m (Krieger et al 1983), and 2.0-3.0 m (Forney 1971). However, spawning depths may exceed $5 \mathrm{~m}$ in lakes with low levels of dissolved organic carbon, where ultraviolet radiation may damage eggs in shallower waters (Williamson et al. 1997; Huff et al. 2004). The length of the egg incubation period, which may be extended by colder water temperatures (Hardy 1978), has been reported as 6-17 days (Powles and Warlen 1988), 8-10 days (Herman et al. 1959), 10-20 days (Whiteside et al. 1985), 14-20 days (Weber and Les 1982), and 25-27 days (Mansueti 1964). Although egg masses are not protected by parental care, egg predation is thought to be rare (Newsome and Tompkins 1985; Almeida et al. 2017). 
The timing, duration, and habitat characteristics of Yellow Perch reproduction in Cheat Lake may differ from those reported elsewhere. Currently, we have little information on Yellow Perch spawning characteristics in Cheat Lake, so information on timing and duration of spawning periods, as well as data on spawning water depths and distances from the shoreline are needed to understand the potential for egg dewatering during periods of lake level drawdown. The primary objectives of this study were to (1) document the timing of Yellow Perch spawning, (2) examine variables with potential influence on spawning habitat characteristics, and (3) examine water level fluctuation as a variable of influence on the timing of spawning, as well as its role in the potential for egg dewatering.

\subsection{Methods}

During spring 2019 and 2020, 40 artificial spawning structures were placed (submerged) at two sites on Cheat Lake; 20 structures at Crammys Run and 20 at Canyon Bend (Fig. 1.1). Lake bottom contours of near-shore areas of Crammys Run were mostly of gradual slope, whereas those of Canyon Bend were mostly steep slopes. Each spawning structure was comprised of a 2.4-m piece of 51-mm diameter PVC pipe (Schedule 40), 10 sections of 1.8-m strands of artificial aquatic plants (reelweeds by LaDredge Outdoors; https://www.reelweeds.com/), and two 2.4-m pieces of $13-\mathrm{mm}$ diameter rebar. These parts were assembled into a $1.8-\mathrm{m}$ tall by $2.4-\mathrm{m}$ long structure (Fig. 1.2). The ends of the PVC pipe were sealed with caps, so that the pipe served as a float. Zip ties were used to attach the tops of the artificial plant strands to the PVC float and 
bottoms of the strands to the rebar. When deployed, the rebar end of the spawning structures rested on the lake bottom, and the structure maintained a vertical position in the water column (owing to the floatation of the PVC pipe). If the water was less than 1.8-m deep at the deployment site, then the 2.4-m piece of PVC pipe floated on the water's surface (Fig. 1.3). When deployed at locations with steep bottom contours, the spawning habitat unit was oriented parallel to the shoreline to reduce water depth variation along the unit's $2.4-\mathrm{m}$ length. A harness of 550 paracord, attached at each end of the PVC pipe, was connected to a longer strand of 550 paracord terminating in an attached location buoy (Fig. 1.2). Each buoy was labeled with a unique number for identification. When the spawning structure was deployed, the tethered buoy floated on the water's surface, providing a way to find and retrieve the structure. We attempted to position the 20 habitat units at each site so that 10 were in the potential dewatering zone and 10 were in deeper areas that were outside of this zone.

The 40 spawning structures were checked daily for the presence of egg masses during the expected spring spawning period. Initially, we considered using underwater cameras to check the spawning structures for the presence of egg masses, but this presented two concerns. First, given an expected range of water turbidity levels, days with poor water clarity would inhibit the efficiency of cameras. Second, we realized that it would be important to remove egg masses from the structures on a daily basis to prevent the double counting of egg masses on consecutive sampling days. Consequently, we checked for egg mass presence by removing the structures from the water. We recorded presence/absence and counted the number of egg masses on each spawning structure. Egg masses were removed from the structures, placed in a bucket of lake 
water, and relocated to nearby areas. Egg masses were relocated to areas with submerged tree habitat and deep water (i.e., areas with a low chance for egg mass dewatering).

Ten egg masses were preserved in $50 \%$ ethanol for estimation of the average number of eggs per egg mass. Egg masses were removed from the ethanol, strained, and measured for length. A gravimetric method was used to determine fecundity (Ganias et al. 2014). Each egg mass was weighed on an Ohaus digital scale. A subsample was removed from the middle of each egg mass and weighed. Each subsample contained greater than 600 eggs. Partitions of the subsample, consisting of 10 to 30 eggs, were placed onto a gridded dish and the eggs were counted under a microscope (Fig. 1.4). Fecundity was estimated with the formula $N=W n / W^{1}$, where $N=$ the number of eggs in the egg mass, $W=$ the weight of the egg mass, $n=$ the number of eggs counted in the subsample, and $W^{1}=$ the weight of the subsample (Ganias et al. 2014). An average value was calculated from eight fecundity estimates. The estimate of the average number of eggs per egg mass was used to calculate total egg numbers by site and year.

Habitat covariates were recorded daily, primarily at the time when spawning structures were checked. Water temperatures were measured at the lake surface in a near-shore area, and at the lake bottom at or near the deepest habitat unit with either a Marcum LX-9 unit or a Hobo tidbit logger. The mean value of the two water temperatures was used as a water temperature covariate. The depth of water at each spawning structure was recorded during deployment and retrieval using a handheld sonar unit. Lunar illumination was recorded as a fraction or percentage of the moon face, a value ranging from 0 (new moon) to 1 (full moon). We measured the distance of the structure to the nearest shoreline's high-water mark (i.e., full pool elevation level) using a laser range finder. We also recorded the distance of the structure to the nearest shoreline's 
current water level. A Secchi disk depth $(\mathrm{cm})$ was also recorded at each site, which provided an index of water turbidity. The elevation of lake water levels in 15-minute increments was obtained from a U.S. Geological Survey gage at the Cheat Lake hydrostation (USGS streamgage 03071590, U. S. Geological Survey 2020). A covariate for water level fluctuation was calculated by subtracting the lake elevation at the time of the structure retrieval from the lake elevation at the time of deployment on the previous day. The water level fluctuation covariate was either negative or positive depending on the direction of change of water level during the time period between daily sampling events. A caveat with this approach is that the actual time of the spawning event is unknown. It is possible that a change in water level elevation could occur after a spawning event. For example, consider a habitat unit that was deployed at 11:00 am and then retrieved with the presence of an egg mass at 11:00 am on the following day. We could document that a water level increase occurred from 4:00 am to 10:00 am on the day of retrieval, but we would not know if the spawning event occurred before or after 4:00 am.

\subsubsection{Data Analysis}

Generalized Estimation Equations (GEE) for binary response (presence/absence of egg masses) with a logit link were used to analyze data of Yellow Perch egg masses on artificial habitat units and associated covariates. The GEE analysis was equivalent to a Logistic Regression analysis but allowed for the use of a correlation matrix structure to properly address spatial clustering of data. In our study, 20 habitat units were clustered together on each sampling day. To select an 
appropriate working correlation structure, we fit models with autoregressive $A R(1)$, compound symmetry, and independent working correlation matrices to our global model and used the correlation information criterion $(\mathrm{CIC})$ to select a working correlation structure (Hin and Wang 2009).

Before analysis, habitat variables were examined with Pearson correlation coefficients, which supported near collinearity $(r=0.98)$ between two distance measures; distances of habitat units to (1) the full pool level on the shoreline and to (2) the current water level at the time of sampling. The distance to the full pool level was retained for analysis, and hereafter referred to as "distance to the shore". Near collinearity was not observed between other variables, resulting in the use of six covariates: water temperature, water depth, lunar illumination, Secchi disk depth, distance to the shore, and lake level fluctuation.

A set of 35 candidate models were fit to the data using GEE analyses with a binomial distribution, a logit link function, and an AR(1) correlation structure (Statistical Analysis System, SAS 9.4; PROC GENMOD) (Table 1.1). Twelve of the candidate models included six single covariate models with a year effect and six single covariate models with a site effect. An additional 20 candidate models of two-variable or three-variable additive effects of covariates included 10 with a year effect and 10 with a site effect. Three models included all six covariates: one with a year effect, one with a site effect, and a global model with both a year effect and a site effect.

We used an information-theoretic approach for model selection and inference. The best model (or suite of competing models) was selected with the Quasi-likelihood Information Criterion $\left(\mathrm{QIC}_{\mathrm{u}}\right.$ ) of Pan (2001). We also estimated QIC distances among models $\left(\triangle \mathrm{QIC} \mathrm{C}_{\mathrm{u}}\right)$ and $\mathrm{QIC}_{\mathrm{u}}$ 
model weights $\left(w_{i}\right)$ following methods of Burnham and Anderson (2002). Models, which represented alternative hypotheses, were considered to be supported by the data if $\Delta \mathrm{QIC}_{\mathrm{u}}$ values were less than 2.0 (Burnham and Anderson 2002). Predicted probability plots (i.e., effect plots) of covariates provided a visual aid for interpretation of model selection results. Further, descriptive statistics of covariates (means and standard errors), histogram plots, and time-series plots aided interpretation of modeling results.

The number of spawning peaks were examined using a mixture model-based approach. For this analysis, we used a time series histogram of total daily counts of Yellow Perch egg masses. Daily counts of egg masses from the two study sites were combined, representing the total daily egg mass count from 40 artificial habitat units. The 2019 and 2020 datasets were examined separately. First, a normal model was fit to the histogram data, which represented a hypothesis of a unimodal peak. Next, we fit four normal mixture models (2-5 mixtures) representing hypotheses for a range of multimodal distributions (JMP, version 12.0.1 SAS Institute Inc. 2015). We used AIC-model selection with small sample size correction $\left(\mathrm{AIC}_{\mathrm{c}}\right)$ to determine the best approximating model (Burnham and Anderson 2002). Using this analysis approach, we determined whether one or more modes or peaks in spawning were present during the 2019 and 2020 spawning periods.

A main focus of this research was on the relationship between fluctuations in water levels of Cheat Lake and the potential for dewatering of egg masses. Daily water level elevation changes of the lake were plotted from data downloaded from the U.S. Geological Survey (USGS 2020). For analysis, we estimated the proportion of egg masses located in potential dewatering zones and included estimates of $95 \%$ profile likelihood confidence intervals. Analyses were based on two 
scenarios. First, we assumed that egg masses were deposited on the lake bottom. In the second scenario, the assumption was that egg masses were deposited onto a structure at a position of 1 $\mathrm{m}$ above the bottom. The range of $0.0-1.0 \mathrm{~m}$ was based on observations of egg mass positions on natural structures in near-shore habitats of Cheat Lake (S. Welsh, Personal observation).

\subsection{Results}

Artificial spawning structures were deployed at the Crammys Run and Canyon Bend study sites for 51 days in 2019 (11 March to 30 April) and 40 days in 2020 (11 March to 19 April). The time periods of egg mass presence on spawning structures in 2019 and 2020, which we refer to as spawning periods, were documented during a 27-day period (21 March to 16 April) in 2019 and a 22-day period (21 March to 11 April) in 2020 (Fig. 1.5). Presences of egg masses were documented 46 and 35 times in 2019, and 13 and 26 times in 2020 on spawning structures at Crammys Run and Canyon Bend, respectively. Typically, a single egg mass was present on a spawning structure, but multiple egg masses were found occasionally on a single spawning structure. In 2019, for 46 instances of egg mass presence on structures at Crammys Run, 36 were single egg masses, 7 represented 2 egg masses, and 3 were for 3 egg masses. Thus, a total of 59 egg masses were found on structures at Crammys Run. For 35 instances of egg mass presence on structures at Canyon Bend, 28 were single egg masses, 5 represented 2 egg masses, and single occurrences were found for 3 and 4 egg masses (45 egg masses in total). In 2020, only 13 single egg masses were found on structures at Crammys Run. For 26 instances of egg mass presence on structures at Canyon Bend, 22 were single egg masses, and 4 represented 2 egg masses (i.e., 30 
egg masses in total). Egg masses were generally attached to the spawning structures in two ways: spiraled around a single artificial vegetation strand or draped over one or more strands (Fig. 1.6).

Ten egg masses were collected in 2020 for estimation of the average number of eggs per egg mass. Two of the 10 egg masses preserved poorly in ethanol, so eight egg masses were examined, resulting in a range of values from 10,538 to 84,570 eggs per egg mass. The average value was 38,237 eggs with a $95 \%$ confidence interval of 20,372 to 56,102 eggs. The ethanol-preserved eight egg masses ranged in length from 580 to $2990 \mathrm{~mm}$. The ethanol preservation altered the gelatinous structure of the egg skeins, allowing the egg masses to stretch to a longer length than that of an unpreserved egg mass. This alteration to the egg skein, however, did not affect the count of eggs. The lengths of egg masses noted during field collection did not extend beyond 2.0 $\mathrm{m}$, but the length of ethanol-preserved eggs was not measured at the time of collection. Based on our average estimate of 38,237 eggs per egg mass, the 59 and 49 egg masses at Crammys Run and Canyon Bend in 2019 contained estimated totals of 2,255,983 and 1,720,665 eggs, respectively. The egg masses at Crammys Run (13) and Canyon Bend (30) in 2020 contained estimated totals of 497,081 and $1,147,110$ eggs, respectively.

\subsubsection{GEE Analysis and Model Selection}

For the GEE analysis, a three-variable additive effects model with a year effect was the only model supported by the data (Table 1.1). The $\mathrm{QIC}_{\mathrm{u}}$-selected model was year + water temperature + water depth + lunar illumination. The GEE parameter estimates for this model (with confidence 
intervals and $p$-values) were year $(0.60,0.15-1.05, p=0.0087)$, water temperature $(0.14,0.0259$ $-0.2475, p=0.0156)$, water depth $(-0.08,-0.15--0.0044, p=0.0378)$, and lunar illumination $(-1.2$, $-1.9002--0.4836, p=0.0010)$.

Plots of predicted probability for presence $=1$ from the GEE analysis, as well as time series plots and descriptive statistics of raw data aided interpretation of the QIC $\mathrm{C}_{\mathrm{u}}$-selected model and its GEE parameter estimates. The predicted probability of egg mass presence was positively associated with water temperature (Fig. 1.7). This relationship is visually supported by an overlay plot of the water temperature time series and the dominant peaks in daily egg mass counts for April 2019 and March 2020 (Fig. 1.5). The predicted probability of egg mass presence was negatively associated with water depth and lunar illumination (Fig. 1.7). The mean values of water depths for habitat units with the presence of egg masses in 2019 (2.7 m) and 2020 (2.6 m) were less than those of all habitat units in 2019 (3.5 m) and 2020 (3.6 m; Table 1.2, Fig. 1.8). The mean values of percent lunar illumination for habitat units with the presence of egg masses in $2019(0.24)$ and 2020 (0.35) were less than those of all habitat units in 2019 (0.38) and 2020 (0.41; Table 1.2). An overlay plot provided visual support for the association of daily egg mass counts with low levels of lunar illumination for the 2019 and 2020 spawning periods (Fig. 1.5).

Several data patterns are worth noting relative to the three covariates (distance to shore, lake level fluctuation, and Secchi disk depth) not supported by the $\mathrm{QIC}_{\mathrm{u}}$-selected model. Egg masses were generally not present in distances exceeding $45 \mathrm{~m}$ to the shoreline (Fig. 1.9), and on average were closer to the shoreline in $2019(23.1 \mathrm{~m})$ and $2020(18.3 \mathrm{~m})$ than that of the average distances of all habitat units in 2019 (24.9 m) and 2020 (25.2 m; Table 1.2). The numbers of egg masses associated with increasing lake levels $(n=68$ ) exceeded those of decreasing lake levels $(n=46$; 
Fig. 1.10). The predicted probability of egg mass presence in 2019 was positively associated with Secchi disk depth, suggesting that Yellow Perch may avoid spawning during turbid water conditions, but the opposite pattern occurred in 2020 (Fig. 1.7). The mean values of Secchi disk depths at Crammys Run and Canyon Bend in 2020 (171 and $156 \mathrm{~cm}$ ) were lower than those of 2019 (208 and $228 \mathrm{~cm})$.

\subsubsection{Spawning Peaks}

A mixture modeling approach supported two spawning peaks during the spawning period of 2019, and a single spawning peak in 2020 (Fig. 1.5). The 2019 spawning peaks occurred in March and April, although the March peak was of lower magnitude than that of April. Spawning in 2020 peaked in March. Further summary of the timing of spawning peaks and associated egg presence on spawning structures between March and April are useful, given that the minimum lake elevation level changes from $261.2 \mathrm{~m}$ asl in March to $263 \mathrm{~m}$ asl in April. In 2019, a total of 19 egg masses were found on 9 structures during 21-31 March, whereas 85 egg masses were found on 72 structures during 1-16 April. In 2020, a total of 32 egg masses were found on 29 structures during 21-31 March, and a total of 11 egg masses were found on 11 structures during 1-11 April. Based on an average estimate of 38,237 eggs per egg mass, the calculated numbers of eggs per time period were 726,503 (March 2019), 3,250,145 (April 2019), 1,223,584 (March 2020), and 420,607 (April 2020). Thus, the number of eggs during April exceeded that of March in 2019, but this relationship was reversed in 2020 . 


\subsubsection{Lake Level Fluctuation}

The 2019 and 2020 fluctuations in water levels during spawning periods were similar but differed from those of some years prior to our study. During the spawning period of 21 March - 16 April 2019, water level elevations of Cheat Lake fluctuated within a range of 263.4-265.1 m asl, a difference of $1.7 \mathrm{~m}$ (Fig. 1.11). During the spawning period of 21 March - 11 April 2020, water level elevations fluctuated within a range of 263.5-265.1 m asl, a difference of $1.6 \mathrm{~m}$ (Fig. 1.11). The ranges of lake elevation fluctuations for 2019 and 2020 spawning periods were minimal relative to the same period of time (21 March - 16 April) for two of the previous three years (2016, 261.8-265.0 m asl, 3.2 m; 2017, 263.4-265.2 m asl, $1.8 \mathrm{~m} ; 2018,261.4-265.2 \mathrm{~m}$ asl, 3.8 m; Fig. 1.12).

Fluctuations in water levels of Cheat Lake were examined in relation to the placement of artificial spawning habitat units and the potential for dewatering of egg masses. As defined previously, the potential for dewatering is based on the elevation of lake water, where drawdown of lake elevations could potentially reach $261.2 \mathrm{~m}$ asl in March and $263 \mathrm{~m}$ asl in April. In Cheat Lake, egg masses are occasionally deposited onto the lake bottom, but generally are draped across structures up to $1.0 \mathrm{~m}$ above the lake bottom, an observation further supported by the locations of egg masses on our artificial structures. We attempted to place half $(0.5)$ of the artificial spawning structures in areas with the potential for dewatering and half $(0.5)$ in areas outside of the potential for dewatering. However, the proportion of habitat units placed in areas 
of potential dewatering of the lake bottom ranged from 0.17 to 0.29 (Table 1.3). Additionally, for these structures in potential dewatering areas, the proportion of egg masses located $1.0 \mathrm{~m}$ above the lake bottom ranged from 0.17 to 0.29 (Table 1.3).

Based on the maximum range of water level fluctuations during the spawning periods of 2019 and 2020, we estimated the proportion of egg masses located in potential dewatering areas (Table 1.3, Fig. 1.13). For 2019, if all egg masses were deposited onto the lake bottom, then 36\% of egg masses (21 of 59) were in potential dewatering areas at Crammys Run, whereas $9 \%$ of egg masses (4 of 45) were in potential dewatering areas at Canyon Bend. With the two sites combined, $24 \%$ of egg masses (25 of 104$)$ were in potential dewatering areas. If egg masses were deposited onto structures at $1.0 \mathrm{~m}$ above the lake bottom, then estimates of egg placement in potential dewatering areas were $64 \%$ (38 of 59), 36\% (16 of 45), and $52 \%$ (54 of 104) for Crammys Run, Canyon Bend, and the two sites combined, respectively. For 2020, if all egg masses were on the lake bottom, then $85 \%$ (11 of 13 ) at Crammys Run, $43 \%$ (13 of 30) at Canyon Bend, and 56\% (24 of 43) at both sites combined were in the dewatering zone. If egg masses were deposited onto structures at $1.0 \mathrm{~m}$ above the lake bottom, then estimates of egg masses in potential dewatering areas were $85 \%$ (11 of 13 ), 63\% (19 of 30), and 70\% (30 of 43 ) at Crammys Run, Canyon Bend, and the two sites combined, respectively (Fig. 1.13).

\subsection{Discussion}


The portability of our artificial spawning structures provided an opportunity to (1) model the relationship of Yellow Perch egg mass presence with a suite of six covariates across two spawning periods, and (2) determine the potential for egg mass dewatering based on water level fluctuation regulation periods. Year-to-year variation in Yellow Perch spawning characteristics were documented, a finding consistent with that reported by others (Weber and Les 1982; Sztramko and Teleki 1997). Also, models supported an association of egg mass presence with water temperature, water depth, and lunar illumination. We expected water temperature to influence the onset of spawning (Dabrowski et al. 1996, Feiner and Höök 2015), but our study demonstrated that water temperature fluctuations influence daily spawning activity during the spawning period, a relationship that has also been reported elsewhere (Starzynski and Lauer 2015). Yellow Perch spawned more often on habitat structures in shallower water, a finding that has long been supported by other studies, but spawning depths up to $6.2 \mathrm{~m}$ were also documented, exceeding typical depths in the range of 0.4-3.7 m as reported elsewhere (Herman et al. 1959; Forney 1971; Krieger et al 1983; Weber and Les 1982). The relationship of egg mass presence with lunar illumination, where spawning typically occurred near the new moon, may be an artifact of our short-term study. Although our modeling approach did not support an influence of water level fluctuations on the timing of spawning during a spawning period, a larger issue is the potential for water level fluctuations, specifically lake level drawdowns, to dewater egg masses. We found year-to-year and between-site variation in estimates of the potential for egg dewatering, which was influenced by the timing of drawdowns, water depths at spawning locations, and bathymetric differences between sites. 
The interaction of photoperiod and water temperature likely influences the onset of spawning in Yellow Perch (Dabrowski et al. 1996, Ciereszko et al. 1997, Kolkovski \& Dabrowski 1998, Feiner and Höök 2015, but see Kayes and Calbert 1979). Also, fluctuations of water temperature following the onset of spawning may influence the length of the spawning period, as well as daily spawning activity and peak periods of spawning (Starzynski and Lauer 2015). In our study, spawning began on March 21 in both years, a consistency that could reflect a photoperiod influence. Water temperatures at the onset of spawning were $6.1^{\circ} \mathrm{C}$ in 2019 and $10.6^{\circ} \mathrm{C}$ in 2020 , and varied throughout the spawning periods ranging from $6.0-14.8^{\circ} \mathrm{C}$ in 2019 , and $8.9-13.4^{\circ} \mathrm{C}$ in 2020. The ranges of spawning temperatures of our two-year study were similar to those reported by Herman et al. $\left(1959 ; 7.2-11.1{ }^{\circ} \mathrm{C}\right)$, Mansueti $\left(1964 ; 8.5\right.$ to $\left.12{ }^{\circ} \mathrm{C}\right)$, Hardy $(1978 ; 5-$ $\left.12.8^{\circ} \mathrm{C}\right)$, Krieger et al. $\left(1983 ; 7-13^{\circ} \mathrm{C}\right)$, and Starzynski and Lauer $\left(2015 ; 11-13^{\circ} \mathrm{C}\right)$. A range of water temperatures for peak spawning $\left(8.5-10.0^{\circ} \mathrm{C}\right)$ was documented by Tsai and Gibson (1971). Based on our GEE analysis of data collected during spawning periods, we found that the predicted probability of egg mass presence was positively associated with water temperature. This relationship with daily egg mass presence and water temperature will likely influence the distribution of spawning efforts between March and April. Water temperature variation may also influence the spawning effort distribution between deeper and shallower water, as water temperature of shallower water general exceeds that of deeper water.

Our study documented several characteristics useful for understanding where Yellow Perch spawn within Cheat Lake, particularly regarding water depth and distance to the shore. Water depth and distance to the shore are often correlated, especially when lake bottom gradients have moderate to steep slopes, but shallow mud flats do not generally follow this pattern. In our study, 
Crammys Run had mostly shallow mud flats with some areas of steep bottom slopes, and Canyon Bend had mostly steep slopes with one shallow mud flat. We realize that our placement of habitat units may have influenced the results. Shallow mud flats (distant from the shore) and deeper habitats generally did not contain many natural spawning structures. Fish may have spawned in these areas because of the presence of our artificial habitat structures, and in the absence of structures, may have otherwise spawned in near-shore areas. From a fishery management perspective relative to lake level drawdowns, our finding that Yellow Perch will spawn in deep water supports an option for placement of spawning structures in water depths outside of the potential dewatering zone.

Our data supported a relationship between egg mass presence and lunar illumination. Most egg masses were present during periods near the new moon, and the dominant spawning peaks in 2019 and 2020 occurred during a waxing crescent. Our review of the literature did not find a reference to a relationship between lunar phase and spawning of Yellow Perch. Lunar synchronization of fish reproduction is not unusual, but it is often associated with marine fishes as a tide-related or reef-related phenomenon (Taylor 1984). Lunar synchronization of reproduction in freshwater fishes, however, has been reported for cichlids (Watanabe 2000), tilapia (Schwanck 1987), and sturgeon (Forsythe et al. 2012). Yellow Perch behavior has been associated with levels of ambient light. Helfman (1979) found that individuals of Yellow Perch increased activity levels during dusk and dawn periods. Yellow Perch generally spawn at night (Raney 1959; Scott and Crossman 1973), although some studies have reported day spawning (Harrington 1947; Hergenradar 1969). Possibly, in our study, the relationship between egg mass presence and lunar illumination is a coincidental artifact and could be better understood with a 
longer time series from additional years of study, or by modeling covariates of cloud cover or sky brightness.

Our modelling results did not support an association between water level fluctuations and egg mass presence. However, egg mass presence was more commonly associated with an increase in lake level than with lake level drawdown. A positive relationship between spawning and increased water levels has been reported for Yellow Perch (Henderson 1985; Kallemeyn 1987), as well as other reservoir species within the littoral zone (Ebel 1979; Ozen and Noble 2002). It is also possible that there is a lag effect associated with lake level fluctuation, where changes in lake levels in days previous may influence the timing of spawning, but we did not address this in our models. Lake level fluctuation at or near the time of spawning, however, may not be the main concern. A larger issue is that eggs in the dewatering zone are vulnerable during their incubation period, which may last from 6-27 days (Mansueti 1964; Whiteside et al. 1985; Weber and Les 1982; Powles and Warlen 1988). Whether or not lake level drawdowns impact the timing of spawning, post-spawn drawdowns can impact eggs during the incubation period.

We are uncertain as to why the number of egg masses on our artificial spawning structures in 2020 were less than that of 2019. For example, we counted 59 egg masses on habitat units at Crammys Run in 2019, and 45 egg masses at Canyon Bend in 2019. In 2020, we counted 13 egg masses at Crammys Run and 30 egg masses at Canyon Bend. However, year-to-year variation in spawning characteristics of Yellow Perch populations is not uncommon (Weber and Les 1982). The between-year difference may be explained in part by a longer spawning season in 2019 relative to that of 2020. Also, an extended period of lake level drawdown for the dredging of a boat launch area at a local marina occurred during the first half of March 2020, which may have 
led to Yellow Perch leaving the shallow Crammys Run area to spawn elsewhere. Possibly, the higher levels of turbidity during the 2020 spawning season reduced the use of artificial spawning structures. It is also possible our counts were biased owing to egg mass detachment from the artificial structures during retrieval, particularly in water deeper than $3 \mathrm{~m}$. Egg masses detached during retrieval of artificial structures on a few occasions for shallow sets $(<3 \mathrm{~m})$, but floated upward with the lifting of the structure owing to their near-neutral buoyancy. Thus, egg masses that detached during shallow-water structure retrieval were observed and counted. For deeper water $(>3 \mathrm{~m})$, it is possible that some egg masses detached during retrieval of artificial structures and may have gone unnoticed and uncounted.

We were particularly interested in water level fluctuations relative to (1) the potential for egg dewatering, and (2) the duration and effort of spawning between March and April, because a 4 $\mathrm{m}$ lake level drawdown is permitted during March, and a $2.1 \mathrm{~m}$ drawdown is permitted during April. Year-to-year variation in egg dewatering potential was documented in our two-year study. During a 27-day spawning period in 2019, we calculated that 52\% (54 of 104) of Yellow Perch egg masses at $1.0 \mathrm{~m}$ above bottom had the potential to be dewatered for both sites (if the lake level was lowered to the minimum elevation of $261.2 \mathrm{~m}$ asl in March, or $263 \mathrm{~m}$ asl in April. For the 22day spawning period in 2020 , the estimate of Yellow Perch egg masses with the potential to be dewatered for both sites was 70\% (30 of 43). Thus, the dewatering of Yellow Perch egg masses would likely be less if the majority of the spawning period and spawning effort occurred during April than in March. During our two-year study, the spawning periods were similar in timing and duration, where spawning occurred from 21 March to 16 April in 2019 and from 21 March to 11 April in 2020. The effort of spawning, however, differed between years, where the majority of 
egg masses in 2019 were found on spawning structures in April, and most egg masses in 2020 were documented during March. Under current lake level regulations, egg losses from dewatering will likely be increased during years when Yellow Perch spawning efforts during March exceed those of April. From a fishery management perspective, single or consecutive years when most of the spawning effort occurs in March could result in reduced recruitment to the adult Yellow Perch population.

In addition to egg masses on our artificial structures, we also observed many egg masses on near-shore natural structures, including submerged and dewatered eggs (Fig. 1.14). Considering that egg masses were present on natural structures at our study sites, as well as expected along near-shore habitats outside of our study sites, then it is reasonable to assume that the number of eggs with dewatering potential is much larger than the 5.6 million eggs documented in this two-year study. Bathymetric characteristics of littoral areas, such as depth, slope, and topography, will likely influence the potential for eggs to be dewatered (Henderson 1985; Zohary and Ostrovsky 2011). Wahlburg (1976) noted that species spawning in shallower water, including Yellow Perch, suffered greater impacts to spawning success from lowered water levels. This was also demonstrated by our data, as the proportion of egg masses that were susceptible to dewatering was lower at Canyon Bend than that at Crammys Run. Nearshore areas at Crammys Run are typically shallower with lower slopes than those at Canyon Bend, resulting in a higher dewatering potential of egg masses at Crammys Run. Based on data from our study, future modeling efforts using bathymetry data could provide insights into the potential for dewatering of eggs at a lake level scale. A potential caveat of our study is that the difference in egg dewatering potential between sites, as well as the overall estimates of egg dewatering potential, 
may be biased by the depths of placement location of our artificial structures. Structures placed in deeper water, which in some areas correspond with farther distances from the shore, may have influenced spawning locations. It is possible that nearshore and shallower areas would have been used in the absence of these deep-water artificial spawning structures. A higher proportion of spawning events in shallower water would have resulted in a higher estimate of egg dewatering potential. From a management perspective, the finding that Yellow Perch will spawn on structures in deeper water outside of dewatering zones provides an option for using deepwater artificial habitats to reduce egg-dewatering potential. However, further studies would be needed to address differences in egg-to-dispersal survival between deep-water and shallowwater spawning events.

Intuitively, the dewatering of Yellow Perch eggs will result in fewer larvae and fewer youngof-year individuals. Less clear is the fish assemblage effect, but we do know that larvae and young-of-year Yellow Perch provide a substantial forage base for Walleye in Cheat Lake (Smith 2018). Predator/prey relationships between Walleye and young Yellow Perch have been reported from other systems (Maloney and Johnson 1957; Forney 1974; Hartman and Margraf 1993; Hansen et al. 1998; Meerbeek et al. 2002; Pierce et al. 2006). Thus, dewatering and associated egg losses may not only impact the Yellow Perch population, but may also have a bottom up effect on the Walleye population, and possibly on other fish populations of Cheat Lake. Although this study focused on one aspect of Yellow Perch life history, additional studies are needed to address potential impacts of water level fluctuations on population dynamics of larval and juveniles (See Henderson 1985; Kallemeyn 1987; Dembkowski et al. 2016). Furthermore, a 
broader ecosystem level study would be useful toward addressing trophic level effects of water level fluctuations (Ploskey 1983; Leira and Cantonati 2008).

\subsection{Conclusions}

Our study demonstrated that Yellow Perch in Cheat Lake spawn in shallow near-shore areas, but will also spawn in a wide range of depths and distances from the shoreline if spawning structure is present. March and April, which are the spawning months of Yellow Perch in Cheat Lake, differ in water level fluctuation regulations; 4-m and 2.1-m drawdowns are permitted in March and April, respectively. The two-year study demonstrated year-to-year variation as to whether peak spawning occurred in March or April. Our study also confirmed the susceptibility of Yellow Perch eggs to dewatering from artificial water level fluctuations. Spawning in deeper water reduces the potential for dewatering of eggs during lake level drawdowns but may be inhibited by a lack of spawning structures. The potential for dewatering of Yellow Perch eggs exceeded $50 \%$ when considering data from both sites and both years of the study. Thus, under current regulations, hydropower drawdown has the potential to reduce egg survival of the Cheat Lake Yellow Perch population by more than half. Under the current lake level drawdown regulations, the largest egg losses will likely occur when Yellow Perch focus their spawning efforts in March as opposed to April. Therefore, considering the documented estimates of dewatered eggs, as well as the additional eggs laid on natural cover that could be dewatered, egg mortality from water level fluctuations in Cheat Lake could be significant. However, our study demonstrated that artificial 
spawning habitat, placed in appropriate locations, may mitigate these losses by providing spawning structure in deeper water.

Acknowledgments We thank Jacob Harrell, Chris Matt, Tamara Matt, Tatiana Matt, Zane Sine, Corey Tucker, and David Wellman for assistance with field work. Funding and support were provided by Cube Hydro, LLC, and the West Virginia Division of Natural Resources. This study was performed under the auspices of West Virginia University IACUC protocol \#1901020543. The use of trade names or products does not constitute endorsement by the U.S. Government.

\section{References}

Almeida LZ, Guffey SC, Krieg TA, Höök TO (2017) Predators reject Yellow Perch egg skeins. Trans Am Fish Soc 146:173-180

Aroviita J, Hämäläinen H (2008) The impact of water-level regulation on littoral macroinvertebrate assemblages in boreal lakes. Hydrobiologia 613:45-56

Becker GC (1983) Freshwater Fishes of Wisconsin. University of Wisconsin Press, Madison

Burnham KP, Anderson DR (2002) Model Selection and Multimodel Inference: A Practical Information-Theoretic Approach. Springer, New York

Brazo DC, Tack PI, Liston CR (1975) Age, growth, and fecundity of yellow perch, Perca flavescens, in Lake Michigan near Ludington, Michigan. Trans Am Fish Soc 104:726-730 
Ciereszko RE, Dabrowskl K, Ciereszko A, Ebeling J, Ottobre JS (1997) Effects of temperature and photoperiod on reproduction of female yellow perch Perca flavescens: plasma concentrations of steroid hormones, spontaneous and induced ovulation, and quality of eggs. J World Aquacult Soc 28:344-56

Clark ME, Rose KA, Chandler JA, Richter TJ, Orth DJ, Van Winkle W (2008) Water-level fluctuation effects on centrarchid reproductive success in reservoirs: a modeling analysis. N Am J Fish Manag 28:1138-1156

Dabrowski K, Ciereszko RE, Ciereszko A, Toth GP, Christ SA, El-Saidy D, Ottobre JS (1996) Reproductive physiology of yellow perch (Perca flavescens): environmental and endocrinological cues. J Appl Ichthyol 12:139-148

De Lima FT, Reynalte-Tataje DA, Zaniboni-Filho E (2017) Effects of reservoirs water level variations on fish recruitment. Neotrop Ichthyol 15(3): e160084

Dembkowski DJ, Willis DW, Wuellner MR (2016) Synchrony in larval yellow perch abundance: the influence of the Moran Effect during early life history. Can J Fish Aquat Sci 73:1567-1574

Ebel W (1979) Effects of hydroelectric projects on fish populations. In: Major DC, Hanchey JR, Willis Jr EJ, Fratus J (eds) Hydropower: A National Energy Resource: 1979 Engineering Foundation Conference, Tidewater Inn, Easton, Maryland, pp 170-176

Echo JB (1955) Some ecological relationships between yellow perch and trout in Thompson Lake, Montana Transactions of the American Fisheries Society 84:239-248 
Feiner ZS, Höök TO (2015) Environmental biology of percid fishes. In: Kestemont P, Dabrowski K, Summerfelt RC (eds) Biology and Culture of Percid Fishes Principles and Practices, Springer, New York

Fitzgerald DG, Dale AR, Thomas MV, Sale PF (2001) Application of otolith analyses to investigate broad size distributions of young yellow perch in temperate lakes. J Fish Biol 58:248-263

Forney JL (1971) Development of dominant year classes in a yellow perch population. Trans Am Fish Soc 100:739-749

Forney JL (1974) Interactions between yellow perch abundance, walleye predation, and survival of alternate prey in Oneida Lake, New York. Trans Am Fish Soc 103:15-24

Forsythe PS, Scribner KT, Crossman JA, Ragavendran A, Baker EA, Davis C, Smith KK (2012) Environmental and lunar cues are predictive of the timing of river entry and spawning-site arrival in lake sturgeon Acipenser fulvescens. J Fish Biol 81:35-53

Gaboury MN, Patalas JW (1984) Influence of water level drawdown on the fish populations of Cross Lake, Manitoba. Can J Fish Aquat Sci 41:118-125

Gaeta JW, Sass GG, Carpenter SR (2014) Drought-driven lake level decline: effects on coarse woody habitat and fishes. Can J Fish Aquat Sci 71:315-25

Ganias K, Murua H, Claramunt G, Dominguez-Petit R, Gonçalves P, Juanes F, Keneddy J, Klibansky N, Korta M, Kurita Y, Lowerre-Barbieri S, Macchi G, Matsuyama M, Medina A, Nunes C, Plaza G, Rideout R, Somarakis S, Thorsen A, Uriarte A, Yoneda M (2014) Chapter 4: Egg production In: Domínguez-Petit R, Murua H, Saborido-Rey F, Trippel E (eds) Handbook of applied fisheries 
reproductive biology for stock assessment and management. Vigo, Spain. Digital CSIC. http://hdl.handle.net/10261/87768

Gasith A, Gafny S (1990) Effects of water level fluctuation on the structure and function of the littoral zone. In: Tilzer MM, Serruya C (eds) Large Lakes, Ecological Structure and Function. Springer, Berlin, Heidelberg, pp 156-171

Hanchin, PA, Willis DW, St Sauver TR (2003) Influence of introduced spawning habitat on Yellow Perch reproduction in Lake Madison, South Dakota. J Freshw Ecol 18:291-297

Hansen MJ, Bozek MA, Newby JR, Newman SP, Staggs MD (1998) Factors affecting recruitment of walleyes in Escanaba Lake, Wisconsin, 1958-1996. N Am J Fish Manage 18:764-774

Hardy Jr JD (1978) Development of fishes of the Mid-Atlantic Bight. An atlas of egg, larval, and juvenile stages, Volume III US Fish and Wildlife Service, Biological Services Program FWS-OBS$78 / 12$

Harrington Jr RW (1947) Observations on the breeding habits of the yellow perch, Perca flavescens (Mitchill). Copeia 1947:199-200

Hartman KJ, Margraf FJ (1993) Evidence of predatory control of yellow perch (Perca flavescens) recruitment in Lake Erie, U.S.A. J Fish Biol 43:109-119

Helfman GS (1979) Twilight activities of yellow perch, Perca flavescens. J Fish Res Board Can $36: 173-179$

Henderson BA (1985) Factors affecting growth and recruitment of yellow perch, Perca flavescens Mitchill, in South Bay, Lake Huron. J Fish Biol 26:449-458 
Hergenrader GL (1969) Spawning behavior of Perca flavescens in aquaria. Copeia 1969:839-841

Herman E, Wisby W, Wiegert L, Burdick M (1959) The yellow perch, its life history, ecology, and management. Wisconsin Conservation Department Publication 228, Madison.

Hill NM, Keddy PA, Wisheu IC (1998) A hydrological model for predicting the effects of dams on the shoreline vegetation of lakes and reservoirs. Environ Manage 22:723-36

Hilling CD, Taylor ND, Welsh SA, Smith DM (2018) Population characteristics of yellow perch in a central Appalachia hydropower reservoir. J Fish Wildl Manag 9:486-495

Hin L-Y, Wang Y-G (2009) Working-correlation-structure identification in generalized estimating equations. Stat Med 28:642-658

Hirsch PE, Eloranta AP, Amundsen PA, Brabrand Å, Charmasson J, Helland IP, Power M, SánchezHernández J, Sandlund OT, Sauterleute JF, Skoglund S (2017) Effects of water level regulation in alpine hydropower reservoirs: an ecosystem perspective with a special emphasis on fish. Hydrobiologia 794:287-301

Huff DD, Grad G, Williamson CE (2004) Environmental constraints on spawning depth of yellow perch: the roles of low temperature and high solar ultraviolet radiation. Trans Am Fish Soc $133: 718-726$

Kallemeyn LW (1987) Correlations of regulated lake levels and climatic factors with abundance of young-of-the-year walleye and yellow perch in four lakes in Voyageurs National Park. N Am J Fish Manage 7:513-521 
Kayes TB, Calbert HE (1979) Effects of photoperiod and temperature on the spawning of Yellow Perch Perca flavescens. Proc World Maricul Soc 10:306-316

Kolkovski S, Dabrowski K (1998) Off-season spawning of Yellow Perch. Progress Fish Cult 60:133136

Krieger DA, Terrell JW, Nelson PC (1983) Habitat suitability information: Yellow Perch. Western Energy and Land Use Team, Division of Biological Services, Research and Development, U.S. Fish and Wildlife Service

Leira M, Cantonati M (2008) Effects of water-level fluctuations on lakes: an annotated bibliography. Hydrobiologia 613:171-184

Logez M, Roy R, Tissot L, Argillier C (2016) Effects of water-level fluctuations on the environmental characteristics and fish-environment relationships in the littoral zone of a reservoir. Fund Appl Limnol 189:37-49

Maloney JE, Johnson FH (1957) Life histories and interrelationships of walleye and yellow perch, especially during their first summer, in two Minnesota lakes. Trans Am Fish Soc 85:191-202

Mansueti AJ (1964) Early development of the Yellow Perch, Perca flavescens. Chesapeake Science $5: 46-66$

McEwen DC, Butler MG (2010) The effects of water-level manipulation on the benthic invertebrates of a managed reservoir. Freshw Biol 55:1086-1101

Meerbeek JR, Isermann DA, Willis DW (2002) Influence of age-0 yellow perch abundance on walleye populations in two eastern South Dakota lakes. Proc S Dak Acad Sci 81:93-99 
Muncy RJ (1962) Life history of the Yellow Perch, Perca flavescens, in estuarine waters of the Severn River, a tributary of Chesapeake Bay. Chesapeake Sci 3:142-159

Nelson WR, Walburg CH (1977) Population dynamics of Yellow Perch (Perca flavescens), Sauger (Stizostedion canadense), and Walleye (S. vitreum vitreum) in four main stem Missouri River reservoirs. J Fish Res Board Can 34:1748-1763

Newsome GE, J Tompkins (1985) Yellow perch egg masses deter predators. Can J Zool 63:28822884

Noble RL (1970) Evaluation of the Miller high-speed sampler for sampling yellow perch and walleye fry. J Fish Res Board Can 27:1033-1044.

Ozen O, Noble RL (2002) Relationship between water level fluctuations and largemouth bass spawning in a Puerto Rico reservoir. Am Fish Soc Symp 31:213-220

Pan W (2001) Akaike's information criterion in generalized estimating equations. Biometrics $57: 120-125$

Pierce RB, Tomcko CM, Negus MT (2006) Interactions between stocked walleyes and native yellow perch in Lake Thirteen, Minnesota: a case history of percid community dynamics. N Am J Fish Manage 26:97-107

Ploskey GR (1983) A review of the effects of water-level changes on reservoir fisheries and recommendations for improved management. Technical Report E-83-3, U.S. Army Engineer Waterways Experiment Station, Vicksburg, Mississippi 
Ploskey GR (1986) Effect of water-level changes on reservoir ecosystems, with implications for fisheries management In: Hall GE, Van Den Avyle MJ (eds) Reservoir Fisheries Management: Strategies for the 80's, American Fisheries Society, Bethesda, Maryland, pp 86-97

Powles PM, Warlen SM (1988) Estimation of hatch periods for Yellow Perch, based on otolith readings from juveniles (age-0). Am Fish Soc Symp 5:60-67

Raney EC (1959) Some young fresh-water fishes of New York. NY State Conserv 14:22-28

Robillard SR, Marsden JE (2001) Spawning substrate preferences of Yellow Perch along a sandcobble shoreline in southwestern Lake Michigan. N Am J Fish Manag 21:208-215

Schwanck E (1987) Lunar periodicity in the spawning of Tilapia mariae in the Ethiop River, Nigeria. J Fish Biol 30:533-537

Scott WB, Crossman EJ (1973) Freshwater Fishes of Canada. Fisheries Research Board of Canada Bulletin 184, Ottawa

Smith CL (1986) Inland Fishes of New York State. New York Department of Environmental Conservation, Albany

Smith D, Welsh S (2015) Biological monitoring of aquatic communities of Cheat Lake, and Cheat River downstream of the Lake Lynn Hydro Station, 2011-2015 FERC project number 2459

Smith D (2018) Evaluation of a re-established Walleye population within a hydropower reservoir recovering from acidification PhD Dissertation, West Virginia University, Morgantown, West Virginia 
Starzynski D, Lauer TE (2015) How temperature affects timing and duration of yellow perch spawning in the Indiana waters of Lake Michigan. J Freshw Ecol 30:445-453

Sutela T, Vehanen T (2008) Effects of water-level regulation on the nearshore fish community in boreal lakes. Hydrobiologia 613:13-20

Sztramko L, Teleki GC (1997) Annual variations in the fecundity of Yellow Perch from Long Point Bay, Lake Erie. Trans Am Fish Soc 106:578-582

Taylor MH (1984) Lunar synchronization of fish reproduction. Trans Am Fish Soc 113:484-93

Taylor N (2013) Assessment of age, diet, and growth of yellow perch (Perca flavescens) in Cheat Lake, West Virginia. MS Thesis, West Virginia University, Morgantown, West Virginia

Tsai C-f, Gibson Jr GR (1971) Fecundity of the Yellow Perch, Perca flavescens Mitchill, in the Patuxent River, Maryland. Ches Sci 12:270-274

USGS, US Geological Survey (2020) National Water Information System data: Cheat Lake near Stewartstown, WV, accessed 15 July 2020 at URL https://waterdatausgsgov/usa/nwis/uv?site no $=03071590$

Wagner T, Falter CM (2002) Response of an aquatic macrophyte community to fluctuating water levels in an oligotrophic lake. Lake Reserv Manag 18:52-65

Walburg, C. H. 1976. Changes in the fish population of Lewis and Clark Lake, $1956-74$, and their relation to water management and the environment. Research Report 79, U.S. Fish and Wildlife Service, Washington, D.C., USA 
Watanabe T (2000) Lunar cyclic spawning of a mouthbrooding cichlid, Cyprichromis leptosoma, in Lake Tanganyika. Ichthyol Res 47:307-310

Weber JJ, Les BL (1982) Spawning and early life history of Yellow Perch in the Lake Winnebago system. Technical Report 130, Madison, Wisconsin: Wisconsin Department of Natural Resources

White MS, Xenopoulos MA, Metcalfe RA, Somers KM (2011) Water level thresholds of benthic macroinvertebrate richness, structure, and function of boreal lake stony littoral habitats. Can J Fish Aquat Sci 68:1695-704

Whiteside MC, Swindoll CM, Doolittle WL (1985) Factors affecting the early life history of yellow perch, Perca flavescens. Env Biol Fish 12:47-56

Wilcox DA, Meeker JE (1991) Disturbance effects on aquatic vegetation in regulated and unregulated lakes in northern Minnesota. Can J Bot 69:1542-1551

Williamson CE, Metgar SL, Lovera PA, Moeller RE (1997) Solar ultraviolet radiation and the spawning habitat of yellow perch, Perca flavescens. Ecol Appl 7:1017-1023

Zohary T, Ostrovsky I (2011) Ecological impacts of excessive water level fluctuations in stratified freshwater lakes. Inland Waters 1:47-59 
Table 1.1. Model selection statistics for 35 candidate models (i.e., alternative hypotheses) fit to egg mass presence/absence data from Cheat Lake, West Virginia. Models included a year effect (2019 and 2020) or site effect (Crammys Run and Canyon Bend). Covariates were water temperature (Temp), water depth (Depth), lunar illumination (Lunar), distance to shoreline (Distance), lake level fluctuation (LLF), and Secchi disk depth (Secchi).

\begin{tabular}{|c|c|c|c|c|}
\hline Model & $\mathrm{QIC}_{\mathrm{u}}$ & Delta & Model L & $\mathrm{Wt}$ \\
\hline Year + Temp + Depth + Lunar & 842.4 & 0.0 & 1.0 & 1.0 \\
\hline Year + Temp + Depth + Distance + LLF + Lunar + Secchi & 850.0 & 7.6 & 0.0 & 0.0 \\
\hline Site + Temp + Depth + Lunar & 853.0 & 10.6 & 0.0 & 0.0 \\
\hline Global & 853.1 & 10.6 & 0.0 & 0.0 \\
\hline Site + Temp + Depth + Distance + LLF + Lunar + Secchi & 854.0 & 11.5 & 0.0 & 0.0 \\
\hline Year + Depth + Lunar & 855.8 & 13.3 & 0.0 & 0.0 \\
\hline Year + Depth + Lunar + Secchi & 857.7 & 15.3 & 0.0 & 0.0 \\
\hline Year + Temp + Depth & 860.4 & 18.0 & 0.0 & 0.0 \\
\hline Site + Depth + Lunar + Secchi & 864.6 & 22.2 & 0.0 & 0.0 \\
\hline Site + Depth + Lunar & 866.0 & 23.6 & 0.0 & 0.0 \\
\hline Year + Lunar & 869.9 & 27.5 & 0.0 & 0.0 \\
\hline Year + Temp & 870.8 & 28.4 & 0.0 & 0.0 \\
\hline Year + Depth + LLF & 870.9 & 28.5 & 0.0 & 0.0 \\
\hline Year + Lunar + Secchi & 871.8 & 29.4 & 0.0 & 0.0 \\
\hline Year + Depth & 872.8 & 30.3 & 0.0 & 0.0 \\
\hline Year + Depth + Distance + LLF & 874.3 & 31.9 & 0.0 & 0.0 \\
\hline Year + Depth + Secchi & 874.5 & 32.1 & 0.0 & 0.0 \\
\hline Year + Depth + Distance & 875.2 & 32.8 & 0.0 & 0.0 \\
\hline Site + Temp + Depth & 877.2 & 34.8 & 0.0 & 0.0 \\
\hline Site + Lunar + Secchi & 878.9 & 36.5 & 0.0 & 0.0 \\
\hline Site + Lunar & 880.1 & 37.6 & 0.0 & 0.0 \\
\hline Year + Distance + LLF & 880.3 & 37.9 & 0.0 & 0.0 \\
\hline Year + Distance & 880.4 & 38.0 & 0.0 & 0.0 \\
\hline Site + Depth + Secchi & 882.2 & 39.8 & 0.0 & 0.0 \\
\hline Site + Depth + LLF & 883.4 & 40.9 & 0.0 & 0.0 \\
\hline Year + LLF & 884.9 & 42.5 & 0.0 & 0.0 \\
\hline Site + Depth & 885.4 & 43.0 & 0.0 & 0.0 \\
\hline Site + Depth + Distance + LLF & 886.5 & 44.1 & 0.0 & 0.0 \\
\hline Site + Temp & 887.0 & 44.6 & 0.0 & 0.0 \\
\hline Year + Secchi & 887.5 & 45.0 & 0.0 & 0.0 \\
\hline Site + Depth + Distance & 887.6 & 45.2 & 0.0 & 0.0 \\
\hline Site + Distance + LLF & 890.9 & 48.5 & 0.0 & 0.0 \\
\hline Site + Distance & 891.1 & 48.7 & 0.0 & 0.0 \\
\hline Site + Secchi & 894.4 & 52.0 & 0.0 & 0.0 \\
\hline Site + LLF & 896.3 & 53.8 & 0.0 & 0.0 \\
\hline
\end{tabular}


Table 1.2. Summary statistics of habitat variables for all spawning habitat units and for those units with presence of yellow perch egg masses $(\mathrm{N}=$ sample size, $\mathrm{SE}=$ standard error, $\mathrm{min}=$ minimum value, and $\max =$ maximum value) .

\begin{tabular}{|c|c|c|c|c|c|c|c|c|c|c|c|c|c|c|c|}
\hline \multirow[b]{2}{*}{ Variable } & \multicolumn{5}{|c|}{ Crammys Run } & \multicolumn{5}{|c|}{ Canyon Bend } & \multicolumn{5}{|c|}{ Sites combined } \\
\hline & $\mathrm{N}$ & Mean & SE & $\min$ & $\max$ & $\mathrm{N}$ & Mean & SE & $\min$ & $\max$ & $\mathrm{N}$ & Mean & SE & $\min$ & $\max$ \\
\hline \multicolumn{16}{|l|}{ All habitat units in 2019} \\
\hline Secchi depth $(\mathrm{cm})$ & 24 & 208 & 11.8 & 44 & 285 & 24 & 228 & 11.1 & 40 & 290 & 48 & 218 & 8.1 & 40 & 290 \\
\hline Water Depth (m) & 465 & 3.2 & 0.12 & 0.31 & 6.1 & 470 & 3.8 & 0.08 & 0.46 & 7.6 & 935 & 3.5 & 0.05 & 0.3 & 7.6 \\
\hline Distance from shore $(\mathrm{m})$ & 465 & 27.2 & 0.79 & 5.0 & 86 & 470 & 22.5 & 0.45 & 7.0 & 47 & 935 & 24.9 & 0.46 & 5.0 & 86 \\
\hline Water temperature $\left({ }^{\circ} \mathrm{C}\right)$ & 24 & 10 & 0.55 & 6.0 & 14.8 & 24 & 10.2 & 0.51 & 7.1 & 14.4 & 48 & 10.7 & 0.37 & 6.0 & 14.8 \\
\hline Lunar illumination & 24 & 0.38 & 0.07 & 0.0 & 1.0 & 24 & 0.39 & 0.07 & 0.0 & 1.0 & 48 & 0.38 & 0.05 & 0.0 & 1.0 \\
\hline \multicolumn{16}{|l|}{ All habitat units in 2020} \\
\hline Secchi depth (cm) & 20 & 171 & 8.7 & 105 & 225 & 20 & 156 & 8.0 & 72 & 225 & 40 & 163 & 6.0 & 72 & 225 \\
\hline Water Depth (m) & 400 & 3.4 & 0.08 & 0.0 & 6.0 & 400 & 3.8 & 0.1 & 0.0 & 8.2 & 800 & 3.6 & 0.06 & 0.0 & 8.2 \\
\hline Distance from shore $(\mathrm{m})$ & 400 & 27.1 & 0.79 & 6.0 & 86 & 400 & 23.3 & 0.56 & 6.0 & 56 & 800 & 25.2 & 0.49 & 6.0 & 86 \\
\hline Water temperature $\left({ }^{\circ} \mathrm{C}\right)$ & 20 & 10.8 & 0.26 & 8.9 & 12.5 & 20 & 11.7 & 0.29 & 10 & 13.4 & 40 & 12.2 & 0.28 & 8.9 & 13.4 \\
\hline Lunar illumination & 20 & 0.41 & 0.08 & 0.0 & 1.0 & 20 & 0.41 & 0.08 & 0.0 & 1.0 & 40 & 0.41 & 0.06 & 0.0 & 1.0 \\
\hline \multicolumn{16}{|c|}{ Habitat units with egg presence 2019} \\
\hline Secchi depth $(\mathrm{cm})$ & 46 & 212 & 8.3 & 44 & 285 & 35 & 249 & 7.4 & 40 & 290 & 81 & 228 & 6.0 & 40 & 290 \\
\hline Water Depth (m) & 46 & 2.4 & 0.16 & 0.91 & 5.4 & 35 & 3.1 & 0.24 & 1.1 & 6.2 & 81 & 2.7 & 0.14 & 0.91 & 6.2 \\
\hline Distance from shore $(\mathrm{m})$ & 46 & 25.3 & 1.7 & 8.5 & 61 & 35 & 20.2 & 1.5 & 9.0 & 47 & 81 & 23.1 & 1.2 & 8.5 & 61 \\
\hline Water temperature $\left({ }^{\circ} \mathrm{C}\right)$ & 46 & 10.9 & 0.37 & 6.0 & 14.8 & 35 & 11.1 & 0.36 & 7.1 & 14.3 & 81 & 11.0 & 0.26 & 6.0 & 14.8 \\
\hline Lunar illumination & 46 & 0.27 & 0.04 & 0.0 & 0.99 & 35 & 0.2 & 0.04 & 0.0 & 0.76 & 81 & 0.24 & 0.03 & 0.0 & 0.99 \\
\hline \multicolumn{16}{|c|}{ Habitat units with egg presence 2020} \\
\hline Secchi depth $(\mathrm{cm})$ & 13 & 162 & 10.2 & 105 & 225 & 26 & 145 & 5.4 & 72 & 195 & 39 & 151 & 5.0 & 72 & 225 \\
\hline Water Depth (m) & 13 & 1.7 & 0.15 & 0.58 & 2.8 & 26 & 3.0 & 0.25 & 0.9 & 5.3 & 39 & 2.6 & 0.2 & 0.58 & 5.3 \\
\hline Distance from shore $(\mathrm{m})$ & 13 & 14.9 & 1.3 & 7.0 & 26 & 26 & 20 & 2.0 & 9.0 & 42 & 39 & 18.3 & 1.4 & 7.0 & 42 \\
\hline Water temperature $\left({ }^{\circ} \mathrm{C}\right)$ & 13 & 10.7 & 0.34 & 8.9 & 12.2 & 26 & 12.3 & 0.19 & 10.1 & 13.4 & 39 & 11.8 & 0.21 & 8.9 & 13.4 \\
\hline Lunar illumination & 13 & 0.27 & 0.1 & 0.0 & 1.0 & 26 & 0.39 & 0.05 & 0.01 & 0.98 & 39 & 0.35 & 0.05 & 0.0 & 1.0 \\
\hline
\end{tabular}


Table 1.3. Proportion of artificial spawning habitat units with and without egg masses located in areas of potential dewatering zones, as defined by minimum lake drawdown regulations. An elevated egg mass is located on structures at $1.0 \mathrm{~m}$ above the lake bottom, and a bottom egg mass is located on the lake bottom. Proportions (Estimate) are provided with lower ( $\mathrm{LCl}$ ) and upper (UCI) 95\% profile likelihood confidence intervals.

\begin{tabular}{|c|c|c|c|c|c|c|c|}
\hline \multirow[b]{2}{*}{ Site } & \multirow{2}{*}{$\begin{array}{l}\text { Egg mass } \\
\text { Location }\end{array}$} & \multicolumn{2}{|c|}{ Dewatering zone } & \multirow[b]{2}{*}{ Total } & \multirow[b]{2}{*}{ Estimate } & \multirow[b]{2}{*}{$\mathrm{LCl}$} & \multirow[b]{2}{*}{$\mathrm{UCl}$} \\
\hline & & outside & inside & & & & \\
\hline \multicolumn{8}{|c|}{ All habitat units 2019} \\
\hline Crammys & Elevated & 268 & 197 & 465 & 0.42 & 0.38 & 0.47 \\
\hline Crammys & Bottom & 353 & 112 & 465 & 0.24 & 0.20 & 0.28 \\
\hline Canyon & Elevated & 298 & 172 & 470 & 0.37 & 0.32 & 0.41 \\
\hline Canyon & Bottom & 390 & 80 & 470 & 0.17 & 0.14 & 0.21 \\
\hline \multicolumn{8}{|c|}{ All habitat units 2020} \\
\hline Crammys & Elevated & 228 & 172 & 400 & 0.43 & 0.38 & 0.48 \\
\hline Crammys & Bottom & 287 & 113 & 400 & 0.28 & 0.24 & 0.33 \\
\hline Canyon & Elevated & 223 & 177 & 400 & 0.44 & 0.39 & 0.49 \\
\hline Canyon & Bottom & 285 & 115 & 400 & 0.29 & 0.24 & 0.33 \\
\hline \multicolumn{8}{|c|}{ Habitat units with egg presence 2019} \\
\hline Crammys & Elevated & 21 & 38 & 59 & 0.64 & 0.52 & 0.76 \\
\hline Crammys & Bottom & 38 & 21 & 59 & 0.36 & 0.24 & 0.48 \\
\hline Canyon & Elevated & 29 & 16 & 45 & 0.36 & 0.23 & 0.50 \\
\hline Canyon & Bottom & 41 & 4 & 45 & 0.09 & 0.03 & 0.19 \\
\hline Combined & Elevated & 50 & 54 & 104 & 0.52 & 0.42 & 0.61 \\
\hline Combined & Bottom & 79 & 25 & 104 & 0.24 & 0.17 & 0.33 \\
\hline \multicolumn{8}{|c|}{ Habitat units with egg presence 2020} \\
\hline Crammys & Elevated & 2 & 11 & 13 & 0.85 & 0.60 & 0.97 \\
\hline Crammys & Bottom & 2 & 11 & 13 & 0.85 & 0.60 & 0.97 \\
\hline Canyon & Elevated & 11 & 19 & 30 & 0.63 & 0.46 & 0.79 \\
\hline Canyon & Bottom & 17 & 13 & 30 & 0.43 & 0.27 & 0.61 \\
\hline Combined & Elevated & 13 & 30 & 43 & 0.70 & 0.55 & 0.82 \\
\hline Combined & Bottom & 19 & 24 & 43 & 0.56 & 0.41 & 0.70 \\
\hline
\end{tabular}




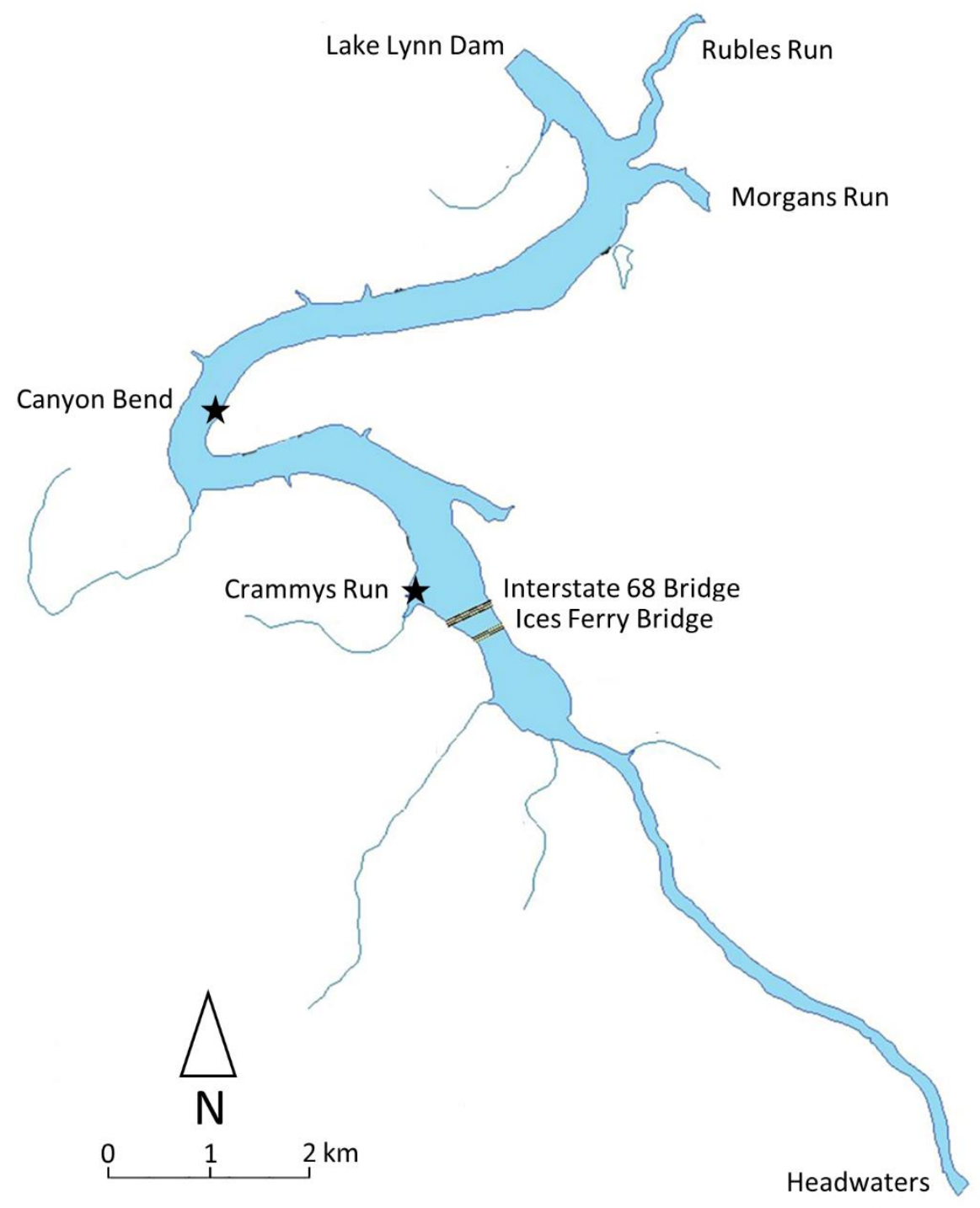

Fig. 1.1. Cheat Lake, located in northern West Virginia, including locations of two study sites (black stars). One site was located near the mouth of Crammys Run, and the other site was on the inside shoreline of Canyon Bend. 

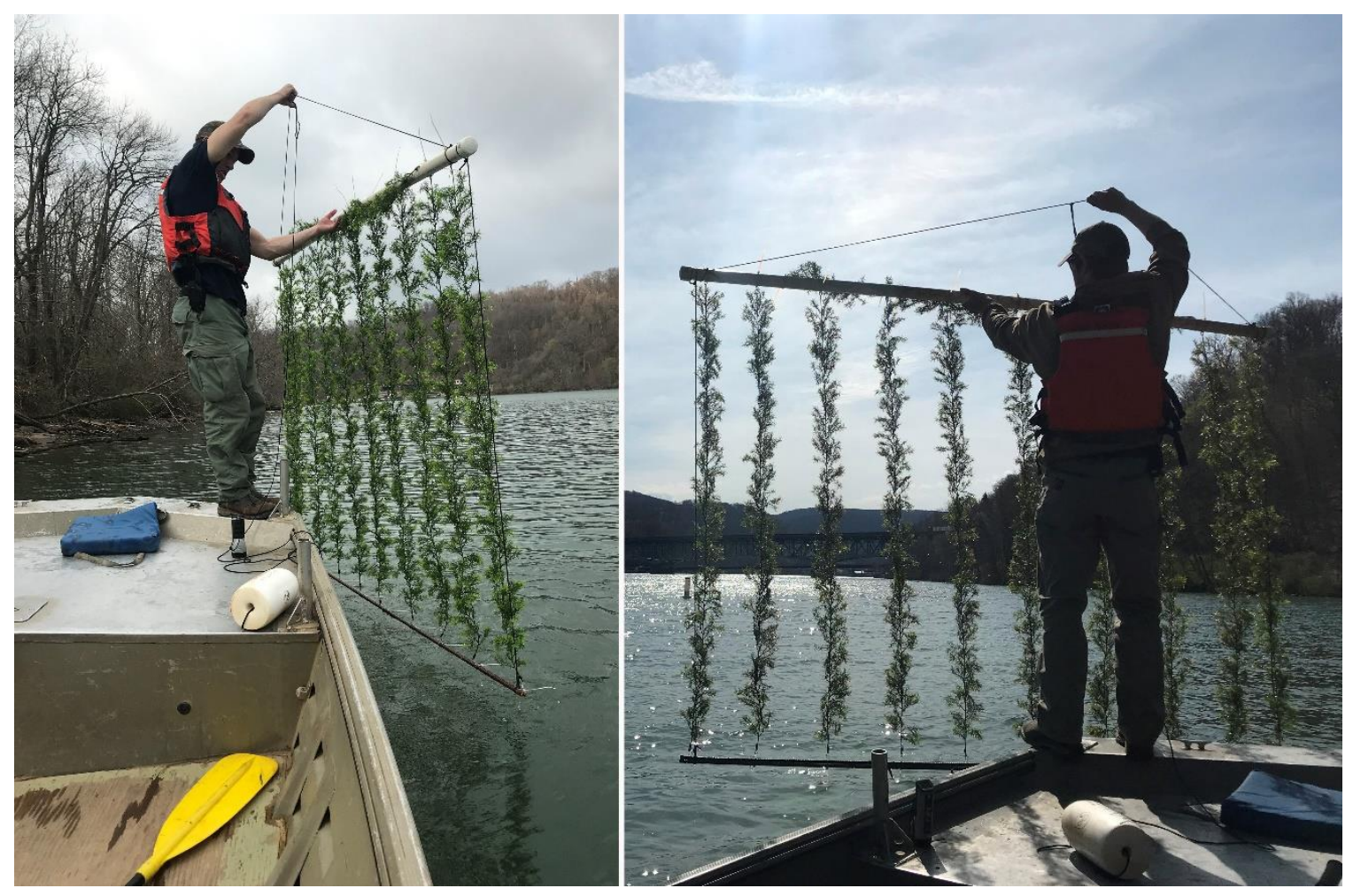

Fig. 1.2. Artificial spawning habitat structures used in a study of Yellow Perch on Cheat Lake, West Virginia. 

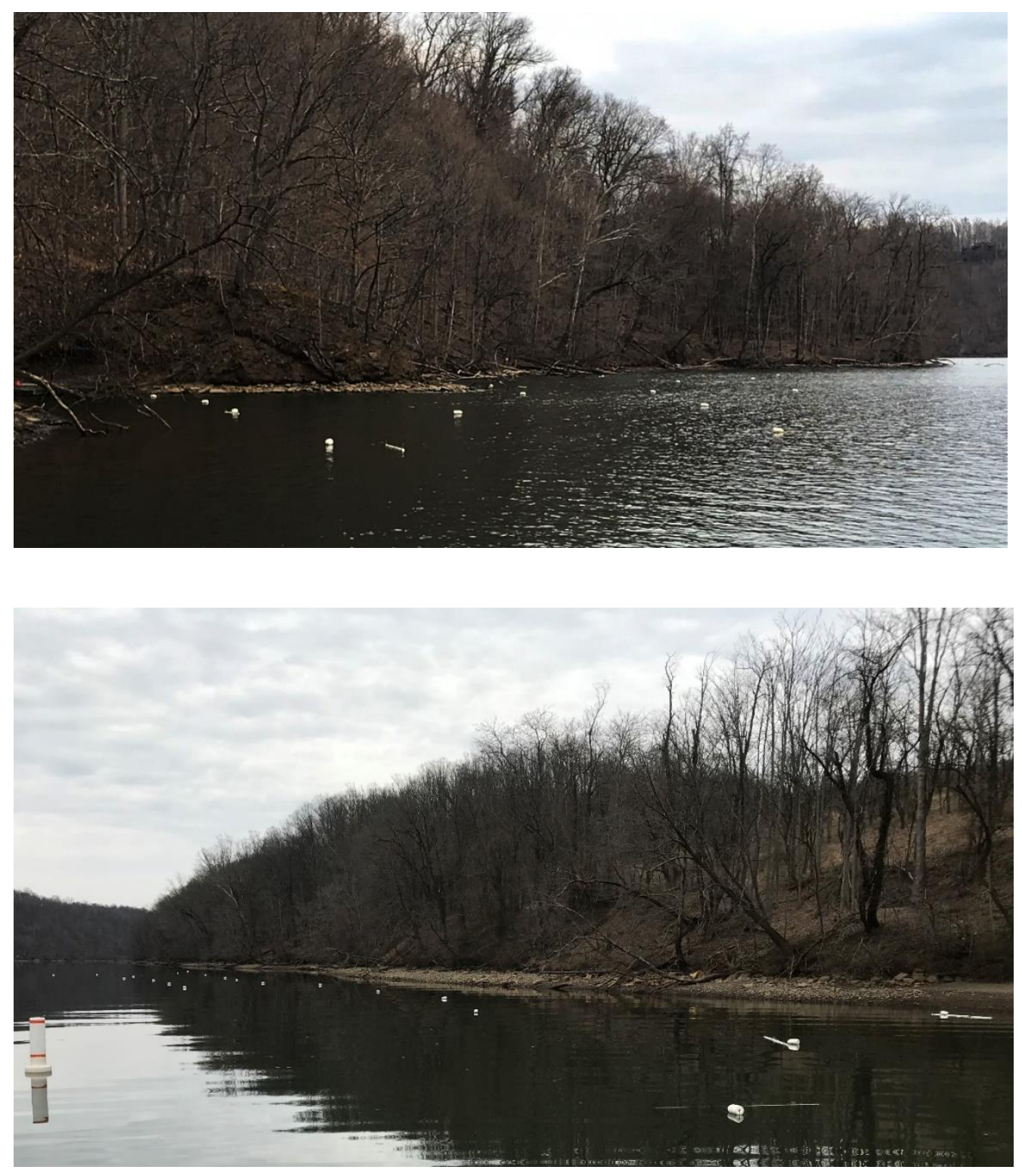

Fig 1.3. Study sites at Crammys Run (top) and Canyon Bend (bottom). White buoys mark the locations of the spawning habitat units. When the water depth was less than or equal to $1.83 \mathrm{~m}$ $(6 \mathrm{ft})$, then the white PVC floats of the spawning habitat units were on top of the water (see bottom right). An organization contact and phone number was printed on each white buoy. One large buoy at each site (see bottom left) was used to alert boaters and provide information about the research project. 


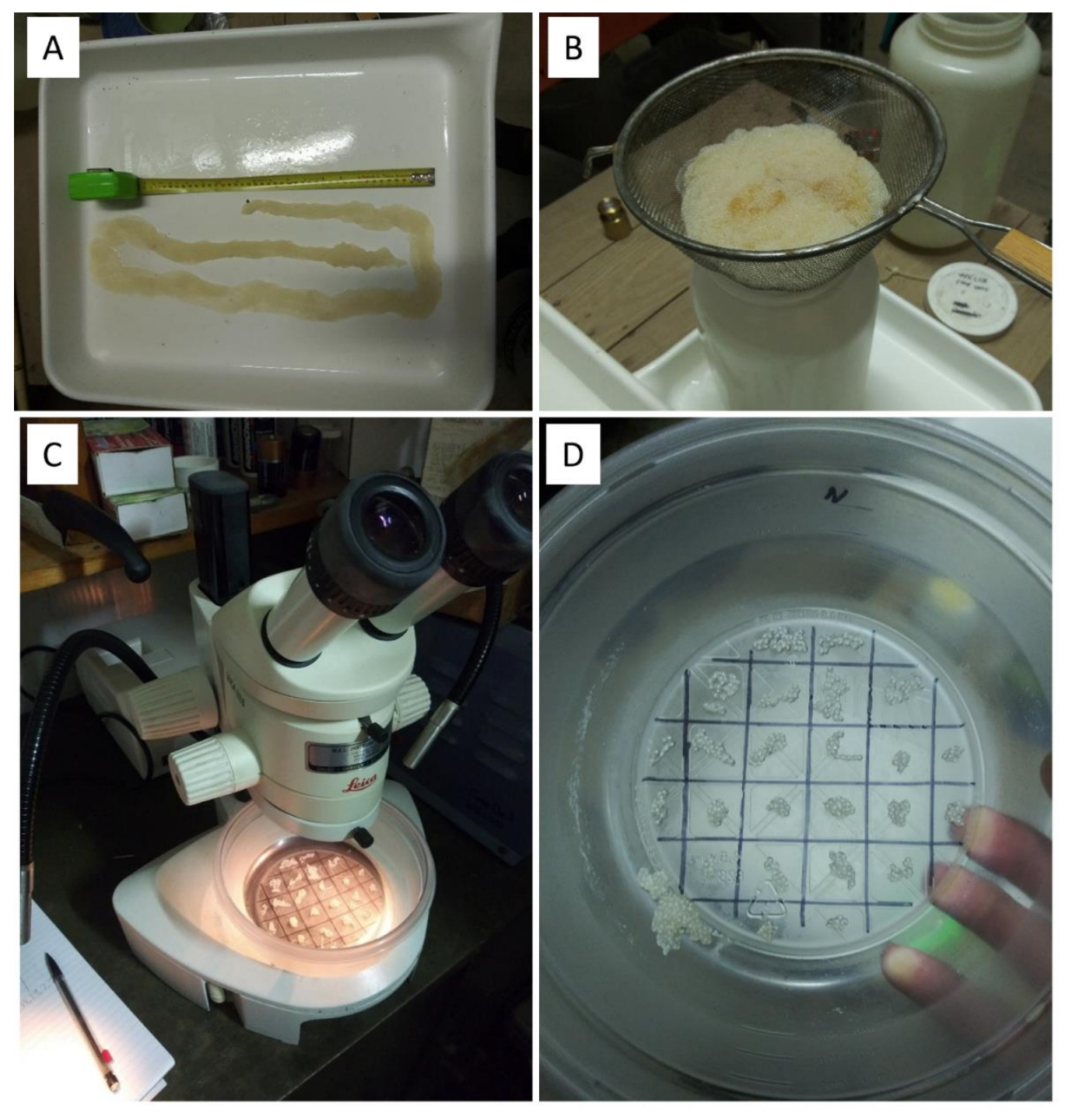

Fig. 1.4. Photographs of the egg counting process, including an ethanol-preserved Yellow Perch egg mass (A), ethanol strained from a preserved egg mass (B), and partitioned subsamples of eggs (C, D). 

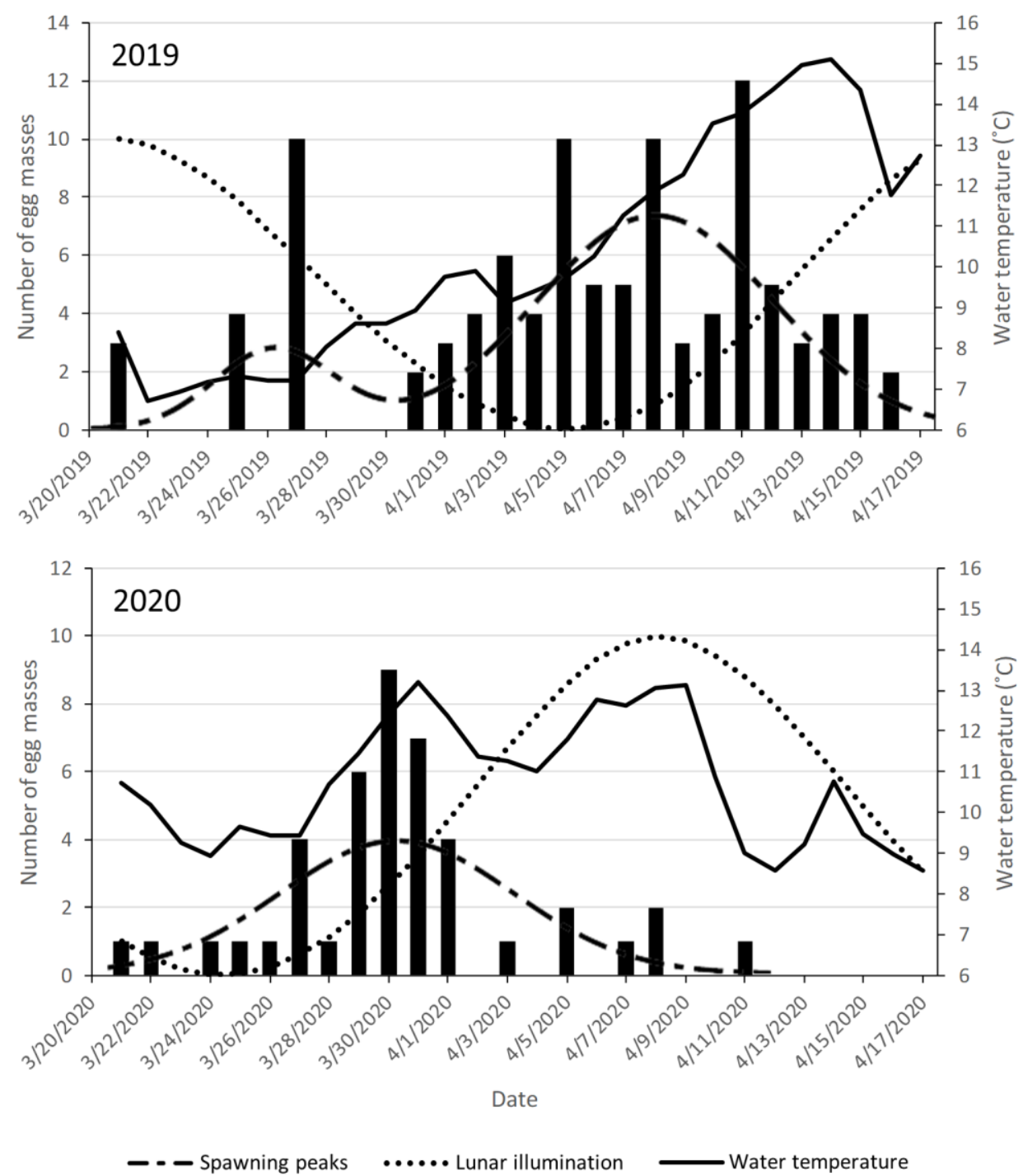

Fig. 1.5. Time series of daily counts of Yellow Perch egg masses on 40 artificial habitat units. Water temperature and lunar illumination are plotted for the spawning periods, which ranged from 21 March-16 April in 2019 and 21 March-11 April in 2020. Spawning peaks were determined by fitting a set of candidate mixture models to daily egg mass counts, where AIC model selection supported a 2-mixture model for 2019, and a unimodal model for 2020. 


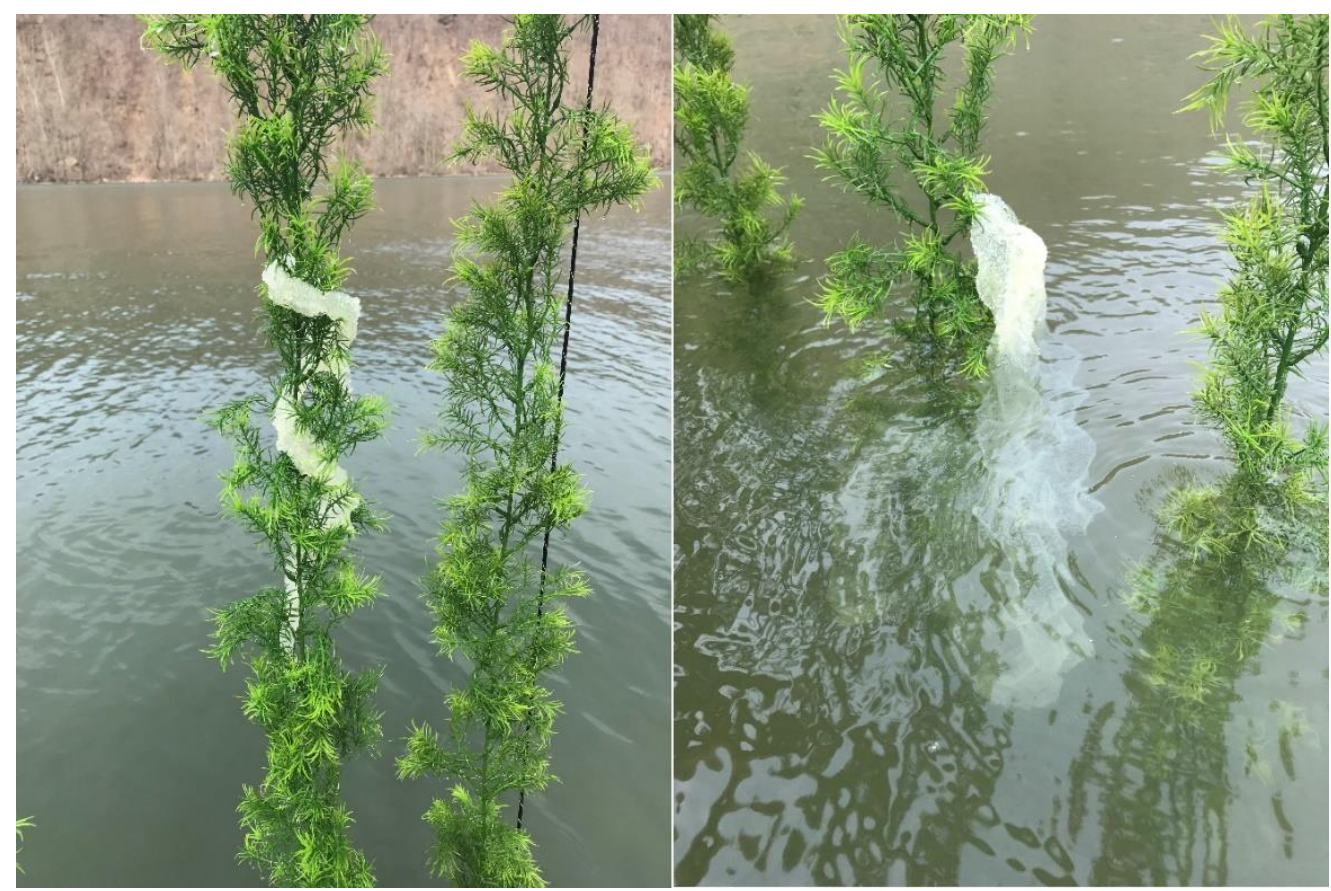

Fig. 1.6. Yellow Perch egg masses spiraled (left) or draped (right) around artificial spawning habitat structures. 

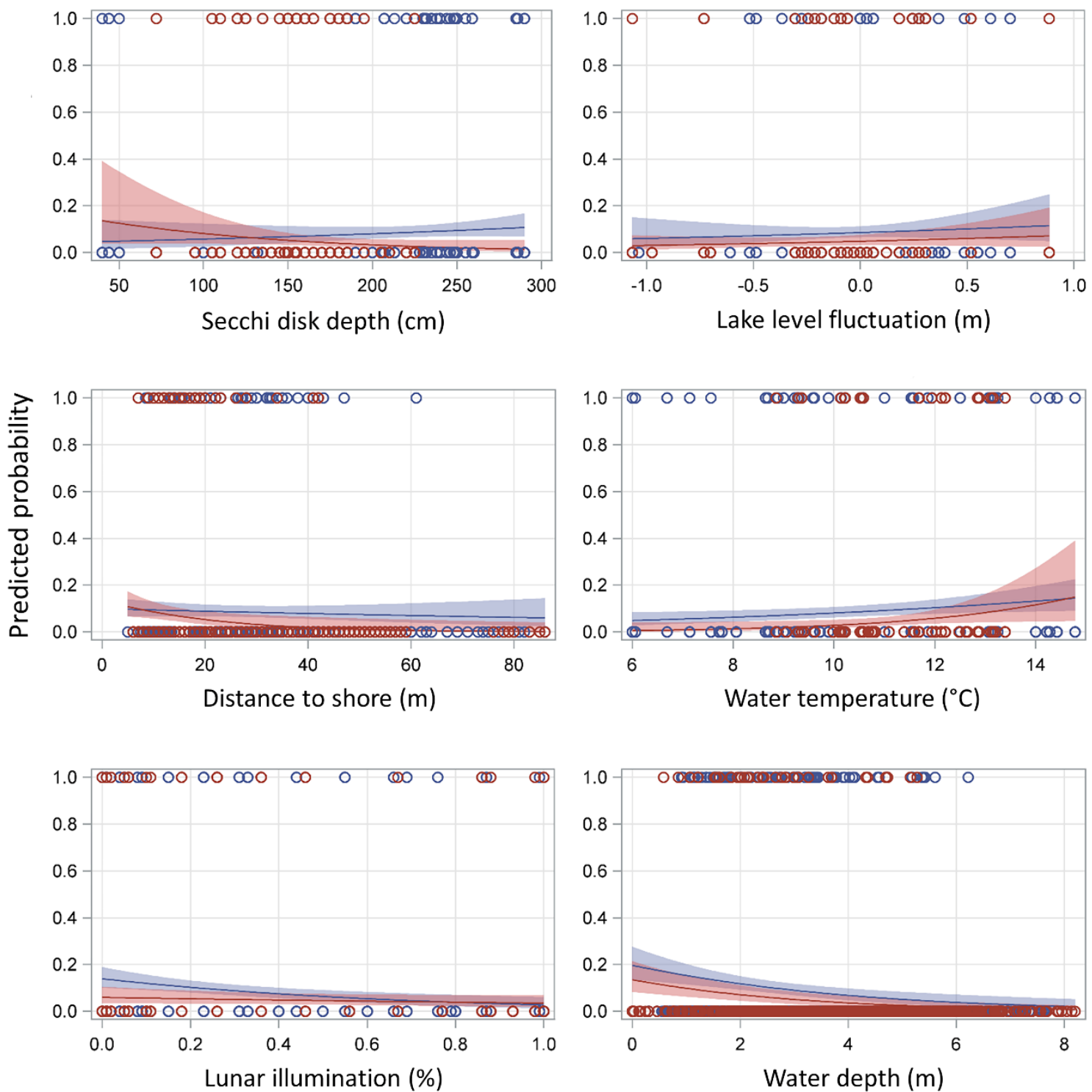

year $\longrightarrow 0-2019 \longrightarrow 0-2020$

Fig. 1.7. Predicted probability of egg mass presence on artificial spawning habitat based on analyses using Generalized Estimating Equations (GEE). Plots depict relationships from 2019 and 2020 of single model covariates; Secchi disk depth, lake level fluctuation, distance to shore, water temperature, lunar illumination, and water depth. 

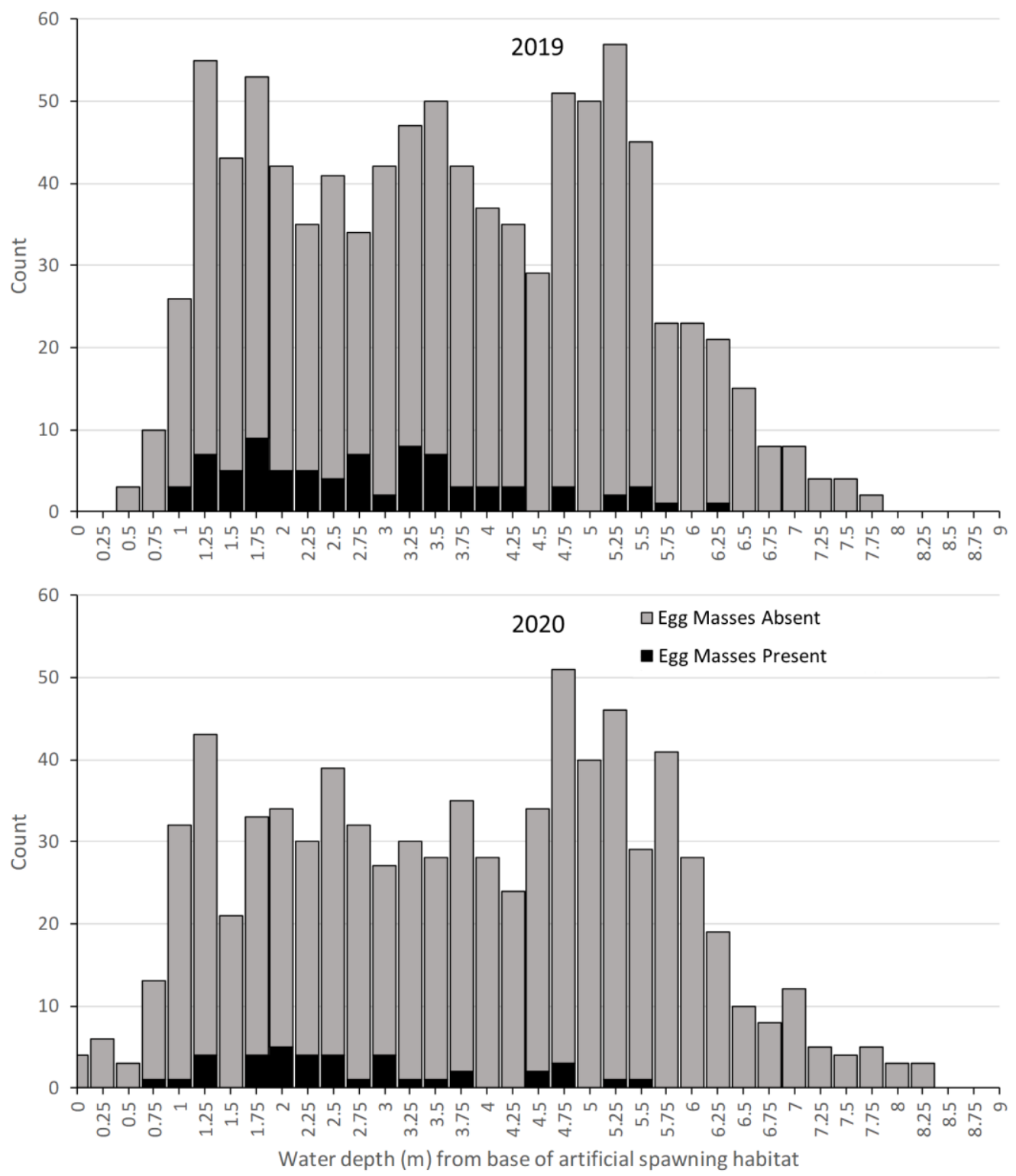

Fig. 1.8. Water depths of artificial spawning habitat units during sampling in 2019 and 2020 with and without the presence of egg masses. 


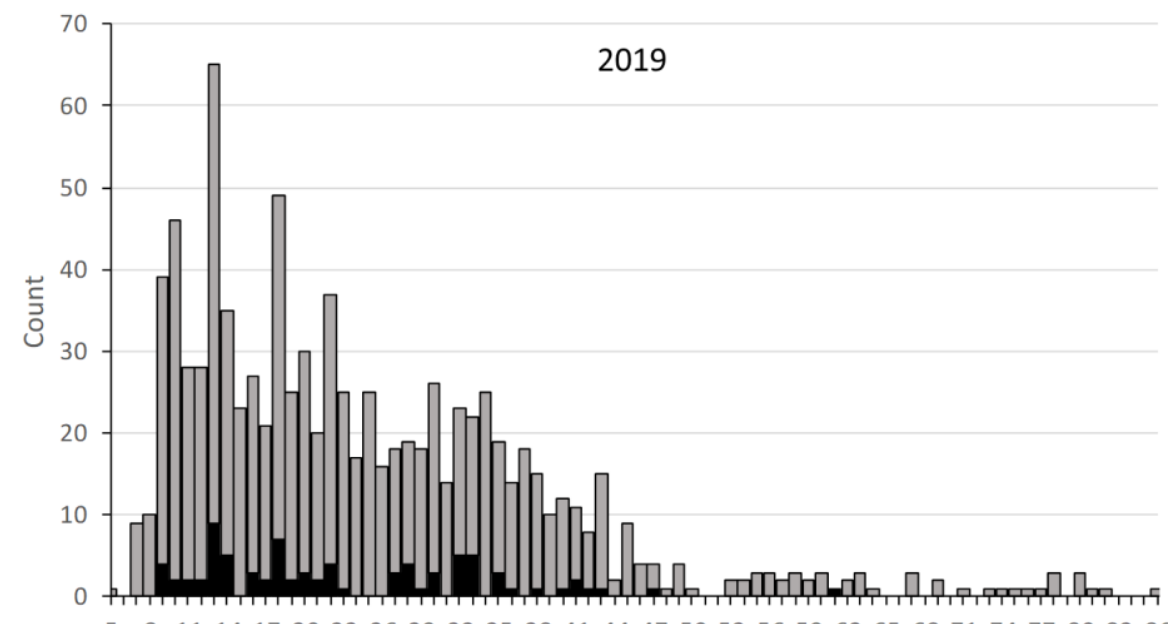

$5 \quad 81114172023262932353841444750535659626568717477808386$

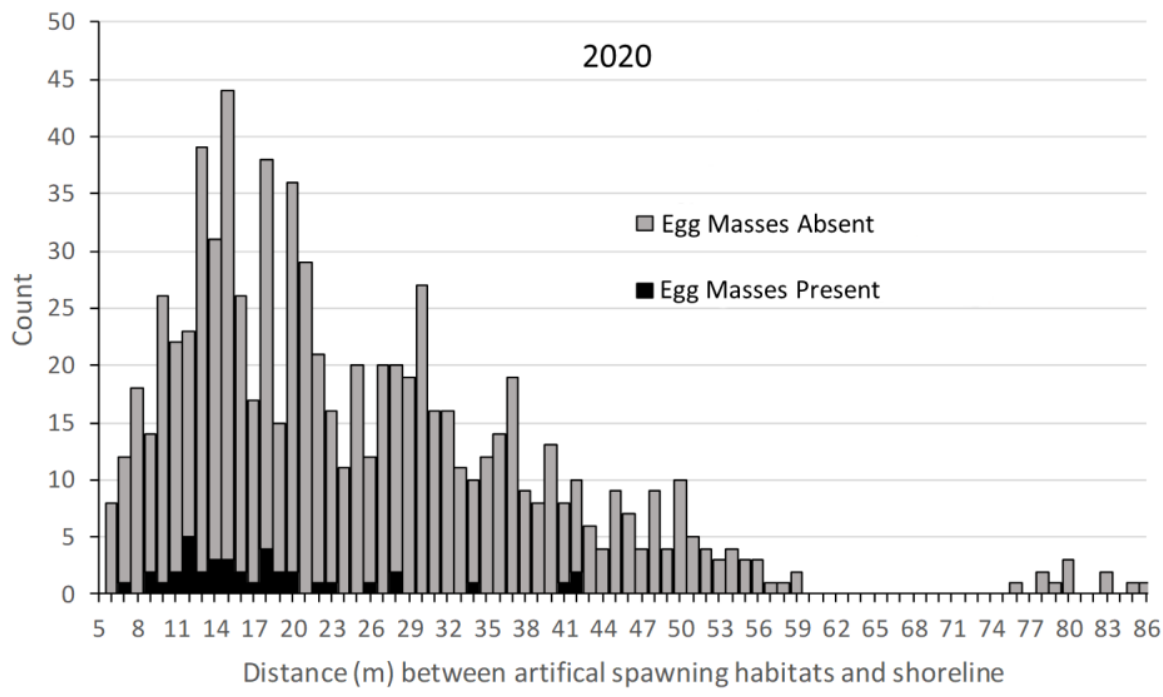

Fig. 1.9. Distances from shoreline of artificial spawning habitat units with and without the presence of egg masses for 2019 and 2020. The $y$-axis is a count of habitat units. Distances were measured from the water surface (directly above submerged habitat units) to the full pool water mark on the nearest shoreline. 


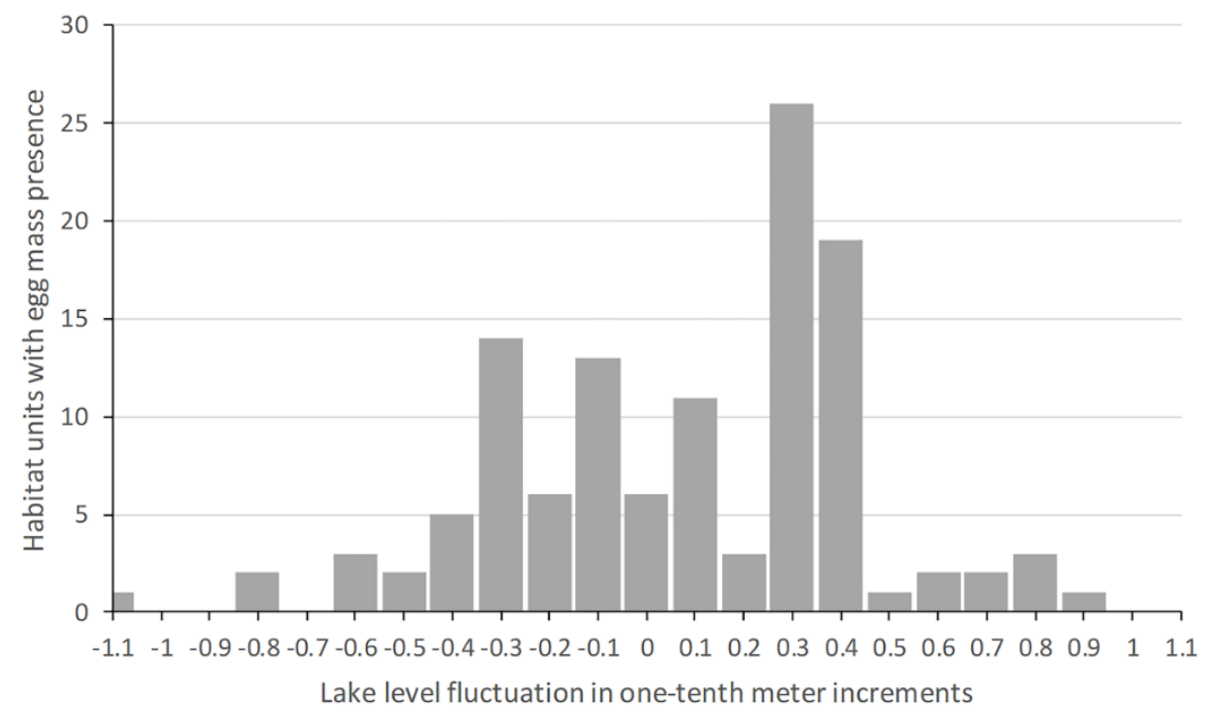

Fig. 1.10. Artificial spawning habitat structures with the presence of Yellow Perch egg masses relative to lake level fluctuations in one-tenth meter increments. 

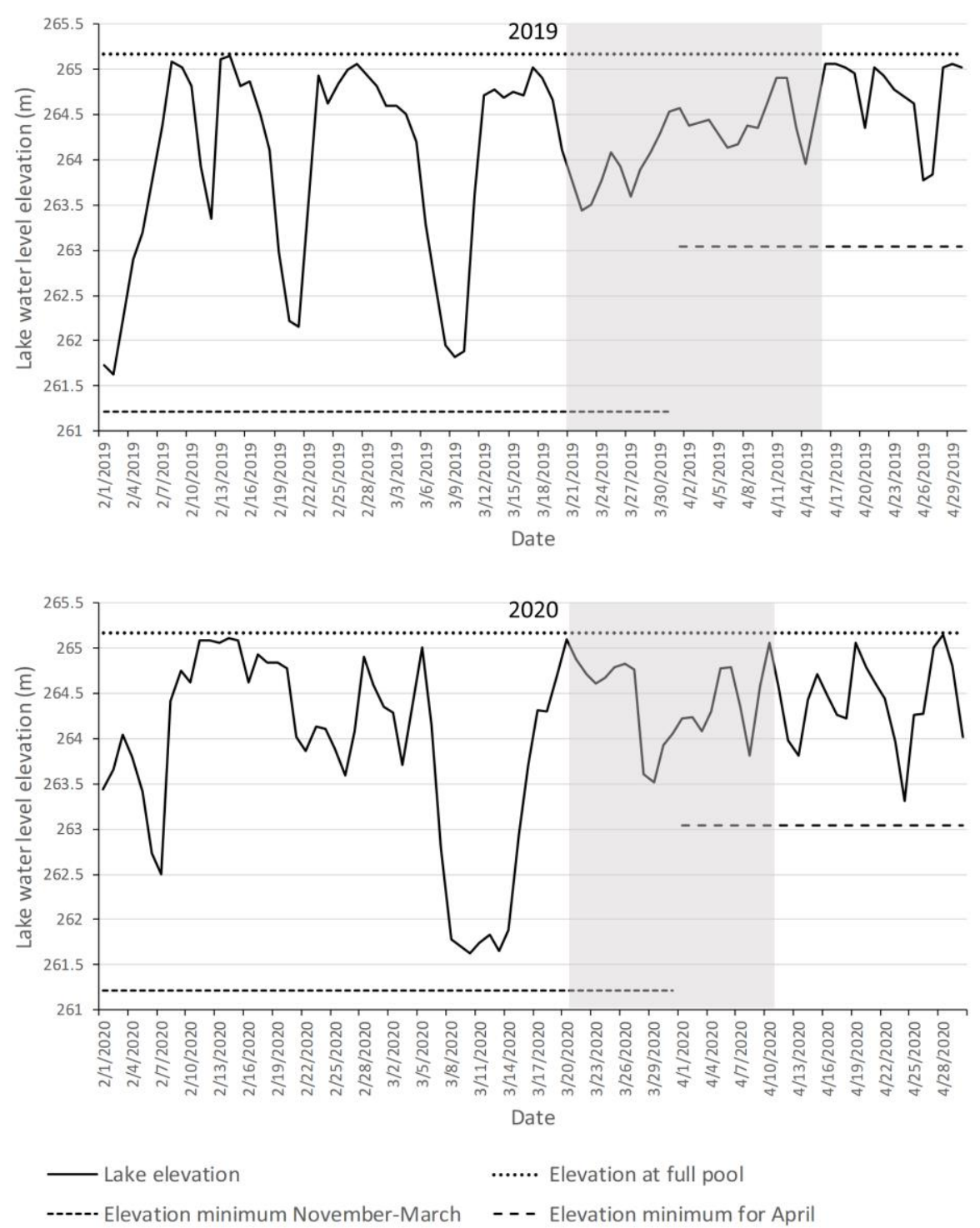

Fig. 1.11. Amplitude, frequency, duration, and timing of fluctuations in surface elevation of Cheat Lake during February-April of 2019 and 2020. Elevation at full pool is $265.2 \mathrm{~m}$. The minimum permitted drawdown elevation is shown for February-March (261.2 $\mathrm{m}$ ) and April (263 m). Gray zones represent spawning periods of Yellow Perch. 

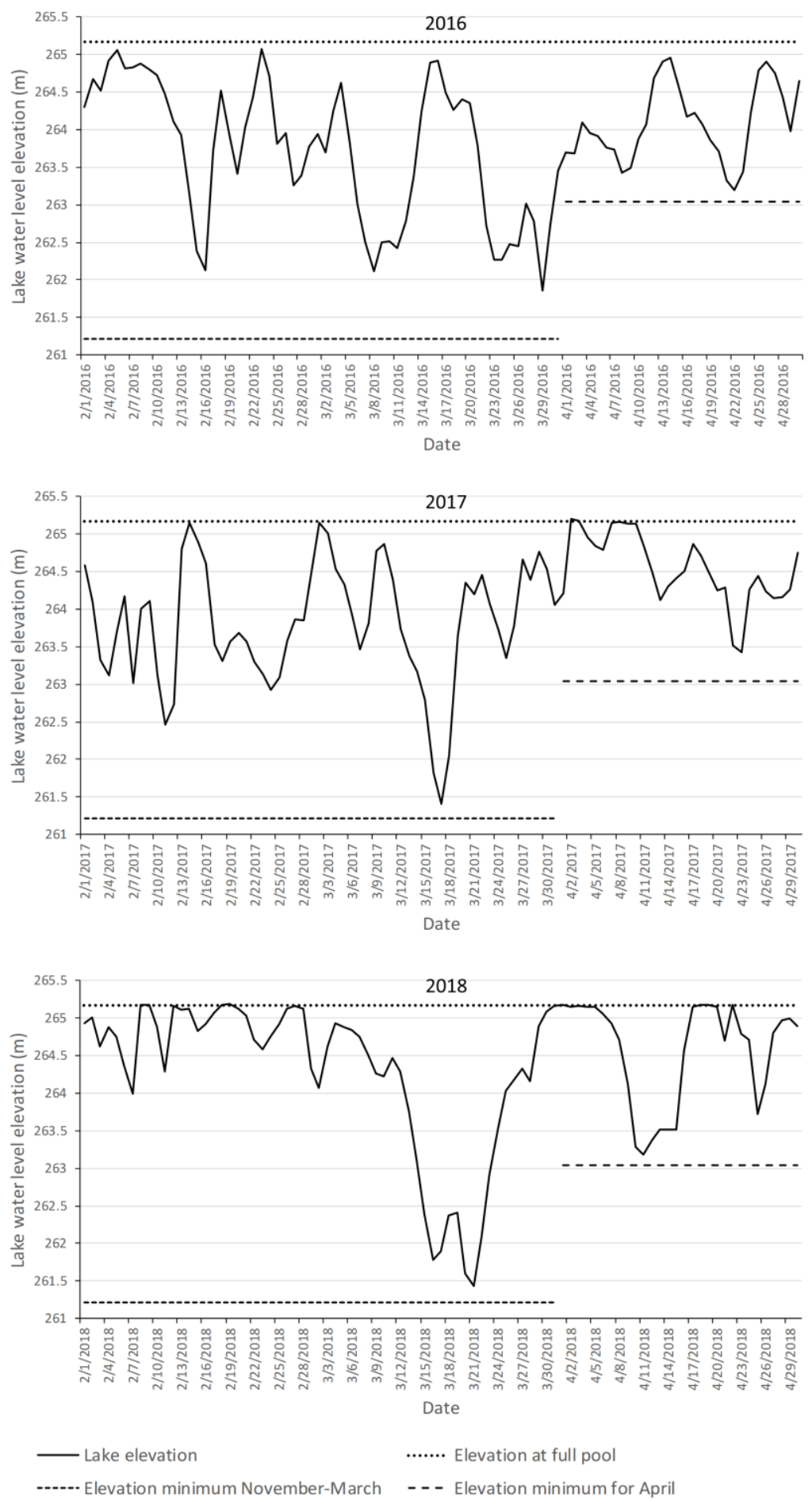

Fig. 1.12. Amplitude, frequency, duration, and timing of fluctuations in surface elevation of Cheat Lake during February-April of 2016-2018. Elevation at full pool is $265.2 \mathrm{~m}$. The minimum permitted drawdown elevation is shown for February-March (261.2 m) and April (263 m). 


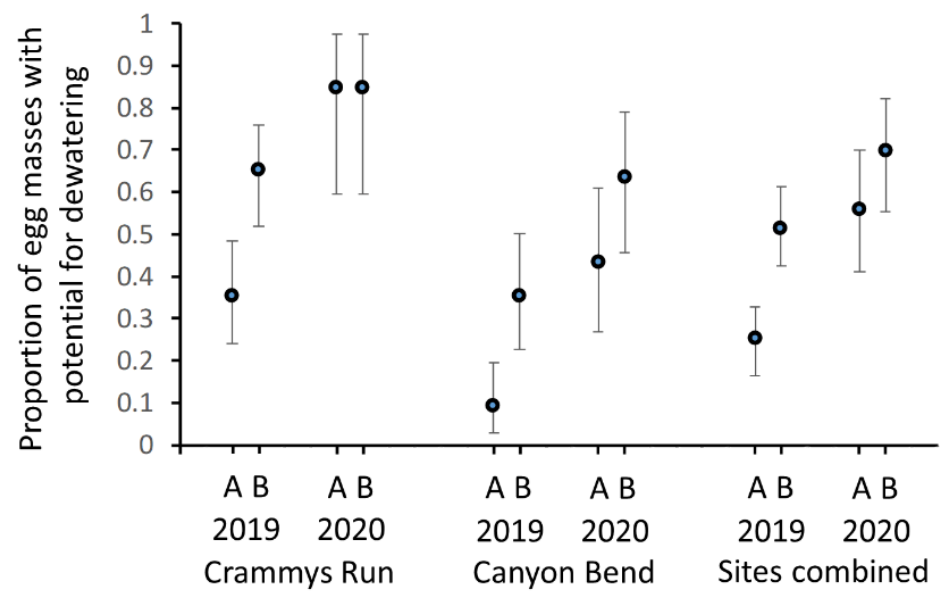

Fig. 1.13. Proportion of egg masses in 2019 and 2020 with potential for dewatering at Crammys Run and Canyon Bend, Cheat Lake, West Virginia. Estimates are based on two scenarios, where egg masses are deposited directly onto the lake bottom (A), or egg masses are deposited onto structures at $1.0 \mathrm{~m}$ above the lake bottom (B). Error bars are $95 \%$ profile likelihood confidence intervals. 

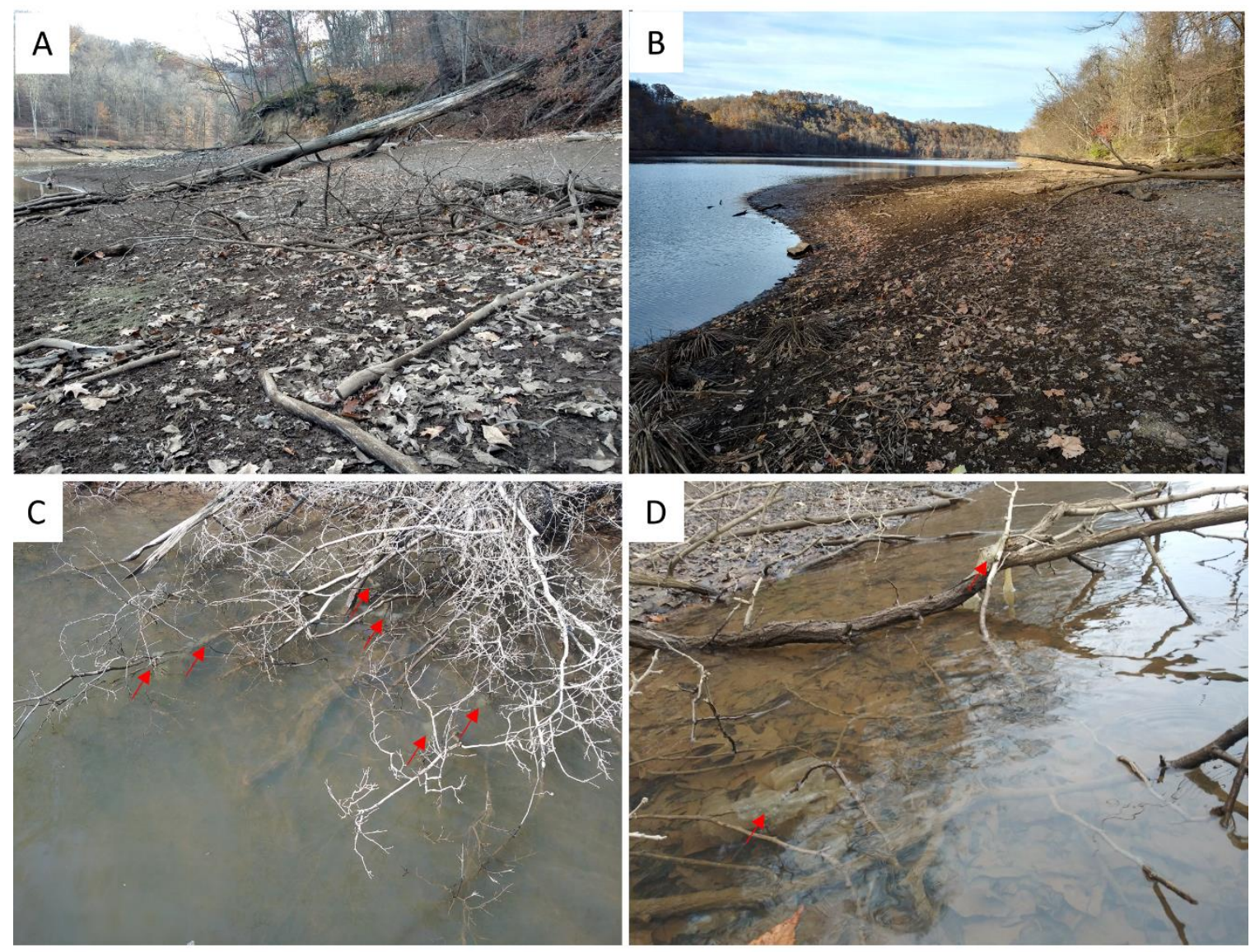

Fig. 1.14. Examples of lake level drawdown of Cheat Lake, West Virginia (A, B), egg masses associated with near-shore natural structure $(C, D)$, and a dewatered egg mass on a natural structure (D). 